\title{
From Energy as a Commodity to Energy as a Service-A Morphological Analysis of Smart Energy Services
}

\author{
Ute Paukstadt · Jörg Becker
}

Accepted: 18 March 2021 / Published online: 19 April 2021

(C) The Author(s) 2021

\begin{abstract}
The Internet of Things penetrates all areas of life and work, giving physical objects the characteristics of digital technologies. Also, in the energy sector, physical products such as photovoltaic systems, battery storage systems, and thermostats are equipped with smart and connectivity components and become smart energy products. Smart energy products enable new types of services that are smart energy services. For example, a smart thermostat can offer an intelligent preheating service based on data collected and analyzed. Against this background, smart energy services offer new business potentials for companies as well as added value for private households. To benefit from this development, companies need an understanding of the characteristics and capabilities of the products and the services building on them. Smart energy services, in particular, appear promising, as services are seen as a bridge to the customer. However, there is little research that supports the design of smart energy services. To close this gap, a morphological analysis of smart energy services along several dimensions is conducted. In highlighting the unique characteristics of smart energy services, the paper provides a more nuanced picture on the nature of smart energy services and their potential in terms of new consumer and business values. Additionally, the phenomenon of consumer-oriented smart energy services will be further conceptualized, and the morphological box can be considered a structured approach for the design of smart energy services.
\end{abstract}

All relevant data is provided in the paper and supplementary material.

This paper was originally submitted and independently peer-reviewed at Business Research, one of SBUR's predecessor journals. It has been accepted by the same Editor-in-Chief for publication in the successor journal SBUR.

U. Paukstadt $(\bowtie)$

Hochschule für Polizei und Verwaltung (HSPV NRW), Münster, Germany

E-Mail: ute.paukstadt@hspv.nrw.de

J. Becker

University of Muenster, European Research Center for Information Systems (ERCIS), Münster,

Germany 
Keywords Smart energy services $\cdot$ Smart services $\cdot$ Classification $\cdot$ Morphological analysis

JEL Classification L86 $\cdot$ L94 $\cdot$ O33

\section{Introduction}

Digitalization is increasingly penetrating the physical world by equipping all objects of everyday life with intelligent components and linking them to the Internet. These objects are referred to as smart products and enable new forms of services, so-called smart services that promise new business opportunities and values for customers (Porter and Heppelmann 2014).

This development also takes place in the energy industry, where smart energy products lead to new smart energy services such as a smart thermostat enabling an intelligent preheating service (Paukstadt 2019). As smart energy products have just begun to enter the end consumer market, for example, in Germany (Alexander von Humboldt Institut and co2online 2018), the private household customer segment is particularly interesting to address by companies and research. Moreover, smart energy technologies enable specific new services for consumers, which were not possible or were financially unattractive earlier, such as peer-to-peer (P2P) marketplaces for the sale of consumer-produced energy (Löbbe and Hackbarth 2017; Rodríguez-Molina et al. 2014).

In the future, Giordano and Fulli (2012) have assumed that consumers may be "more interested in the services that can be obtained through electricity, rather than in electricity per se" (p. 253). In general, electricity is a homogenous commodity and, therefore, a low-involvement topic for consumers (Kahma and Matschoss 2017). As a result, researchers have proposed shifting from supplying energy as a commodity to the provision of innovative (smart) energy services (Apajalahti et al. 2015; Hamwi et al. 2016; Wünderlich et al. 2015). Technology advances and changing market conditions such as the upcoming smart meter rollout in many countries like Germany have rendered the design of smart energy services not only appealing but also necessary for businesses to profit from this development and to remain competitive (Bischoff et al. 2017; Porter and Heppelmann 2014).

Due to their novelty and low adoption in the end consumer market, the potential of smart energy services for creating new business opportunities for companies is not well-understood. With regard to the design of smart energy services, academia has not yet provided theories or explanations. Moreover, as with smart services in general (Maglio and Lim 2016; Wünderlich et al. 2015), the design of smart energy services is challenging. A particular challenge stems from bundling attractive marketable offerings, since there are several design elements that have to be determined. The complexity of service design increases, since smart energy technologies and the corresponding services are an emerging phenomenon that continuously add new capabilities to the service design space. Accordingly, the vast number of new service innovations and their configuration options make it difficult for research and practice to gain an overview of the different possibilities for service design. Moreover, there 
is limited knowledge on the single important characteristics of smart energy services and the different capabilities of existing smart energy services (e.g., regarding their data-driven potential) (Paukstadt 2019).

In terms of smart energy services, research has investigated single services in the past, such as smart metering (Wunderlich et al. 2012), and specific aspects, such as willingness to pay (Richter and Pollitt 2018). To date, research has assisted energy utilities in selecting potential smart energy services (Goldbach et al. 2018). Few academics have analyzed different smart energy services and their design options along several dimensions (one exception is the work of Salah et al. 2017).

Since research has not yet provided theories and explanations on the design of smart energy services for new business and customer values, this study is an exploratory study and provides an analysis and classification of the new developments in the consumer-oriented smart energy service market which can serve as a fundament for future quantitative and qualitative studies. Against this background, this paper explores the following research question: How can smart energy services addressing private households be described in terms of relevant characteristics? To answer the research question, a morphological analysis of smart energy services based on existing literature and empirical knowledge is conducted (Zwicky 1948, 1967). In highlighting the unique characteristics of smart energy services, the paper provides a more nuanced picture on the nature of smart energy services and their potential in terms of new consumer and business values. Additionally, the phenomenon of smart energy services will be further conceptualized, and the morphological box can be considered a structured approach for the design of smart energy services.

Since most research on (smart) energy services originates in the sustainability and energy journals, it concentrates on the perspective of utilities and regulation issues. We, therefore, introduce another perspective and look at smart energy services through a service science lens (Beverungen et al. 2019; Vargo and Lusch 2008) and by employing the smart product concept from Porter and Heppelmann (2014). Thereby, this study is acontextual in its approach (e.g., it is not bound to regulation in a specific region or specific companies such as utilities).

The next section reviews relevant background literature to conceptualize smart energy services. From these foundations the methodology for building the morphological box is proposed in Sect. 3. In the following Sect. 4, different types of smart energy services are presented which are derived from the literature. Building on this, Sect. 5 introduces the morphological box. Sect. 6 demonstrates the application of the box to real cases and exemplary illustrates the use of the morphological box for analyzing four smart energy services. Finally, the findings together with the contribution and limitations are discussed in Sect. 7 before summing up the research in Sect. 8 .

\section{Research Background}

For the underlying understanding of smart energy services, firstly general domainrelated knowledge is applied to consider energy domain specifics as well as extant definitions of smart energy (services). Furthermore, research on smart (connected) 
products and services is used that is mainly grounded in the information systems and business research (respectively with those related) disciplines. Particularly, the widely used conceptualizations by Porter and Heppelmann (2014) regarding smart connected products and by Beverungen et al. (2019) regarding smart services guide the upcoming research endeavor. As a theoretical lens, the service-dominant (S-D) logic helps to better understand the intertwined nature of smart energy products and services, and thus explains the general structure of the following morphological box later on. The section mainly relies on former published research (Paukstadt et al. 2019a, b).

\subsection{The Energy Value Chain}

To better understand the different smart energy services and the corresponding changes in the energy industry, it makes sense to look at the traditional energy value chain. Fig. 1 illustrates the value chain which shows the processes from generation, supply to final consumption (NIST 2014; Richter 2012).

After energy is generated in central bulk power plants, it is fed into the grid, eventually traded in electricity markets and led over transmission networks with high voltage towards distribution networks that supply the end customer with low voltage electricity. The retail part mainly consists of administrative tasks such as the purchase of energy from producers and traders and selling it to end customers as well as metering and billing. The last step of the energy value chain is consumption. With the upcoming smart grid and energy technologies the traditional value chain undergoes several changes. Energy storage systems play an increasingly important role as volatile renewable energy plants constitute a higher amount of energy generation. The fluctuation in the generation also leads to higher significance of the consumption process through demand side management. Moreover, possibilities for trade change, for instance, new markets emerge, where consumers and aggregators buy and sell energy (NIST 2014). Since private households not only consume but also generate, manage and store their own energy (and thus become "prosumers") there are growing opportunities to provide services for residential customers along generation, supply and consumption processes, for example, with consultation, installation, financing, operation, maintenance, and warranties (Richter 2012). In the future, the smart energy value chain is expected to transform into a smart energy value network due to the increase of bidirectional information flows between the energy resources and actors and growing importance of prosumer resources and decrease of centralized production (International Energy Agency 2015; Shomali and Pinkse 2016).

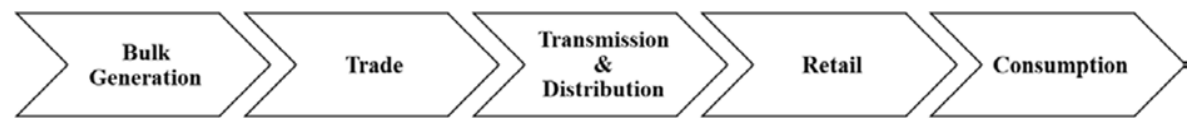

Fig. 1 Traditional Energy Value Chain. (Adapted from NIST (2014) and Richter (2012)) 


\subsection{Smart Energy Products and Services}

Kranz et al. (2015) define smart energy "as the use of ICTs [Information and Communication Technologies] in energy generation, storage, transmission, and consumption, aiming at increasing efficiency, encouraging eco-friendly behavior, and decreasing the emission of GHG [Greenhouse Gas]" (p. 8). A smart energy system is a cyber-physical system consisting of various sensor and actuator networks, which are integrated with the physical electricity grid infrastructure (Kranz et al. 2015).

Lund et al. (2012) regard smart energy systems as the broader concept in contrast to smart grid. A smart grid is an ICT-enhanced intelligent electricity grid that is able to integrate renewables and coordinates the unsteady energy production with demand (Goebel et al. 2014). Thus, a smart grid is part of an overall smart energy system that refers to several kinds of energy, not only electricity (Goldbach et al. 2018; Lund et al. 2012). Furthermore, a smart energy system can exist on a business or household level (e.g., by using a photovoltaic (PV) system, storage, and intelligent energy manager), and therefore it does not necessarily need to be connected to the overall power grid (Van Dam et al. 2010; Weiller and Neely 2014).

Smart energy can be subsumed as a topic of the Internet of Things which assumes that every physical object becomes part of the Internet. Thereby, smart energy technologies such as an intelligent photovoltaic system facilitate bidirectional data and information flows between the environment, the consumer, and other objects (Fleisch et al. 2014; NIST 2014). In accordance with Porter and Heppelmann (2014) and Beverungen et al. (2019), smart energy systems are looked at in the form of smart products that consist of physical objects embedding intelligent components, like micro-processors, sensors, controls, software, data storage, and a connectivity component that together enable new monitoring, control, optimization and autonomous capabilities and facilitate an intelligent energy management. Since the focus is on the household level, different smart energy products are used to manage the energy flows intelligently by gathering data from the environment or even interacting and communicating with the environment and other objects (Fleisch et al. 2014). The different smart energy products for the consumers are depicted in Fig. 2. Some are rather production-oriented, whereas others focus on the consumption side or serve to connect the different products.

To analyze the components of a smart product and to assess their potential for new business options such as commercial services, it is useful to apply a layered smart product architecture such as the architecture proposed by Fleisch et al. (2014). Following this, a smart energy system can be structured in distinctive layers representing the respective components deployed and functionalities provided by the system. The layers build up on each other and the lower layers enable the higher layer functionalities (Fleisch et al. 2014). Building on these general architectures, Fig. 3 shows a smart energy product architecture.

On the bottom layers, physical objects such as thermostats are rooted. Equipped with sensors, they gather data and send information to the higher layers. Through a connectivity layer the object can communicate with the internet as well as other objects and can use cloud services for data analytics. Based on the underlying layers, 


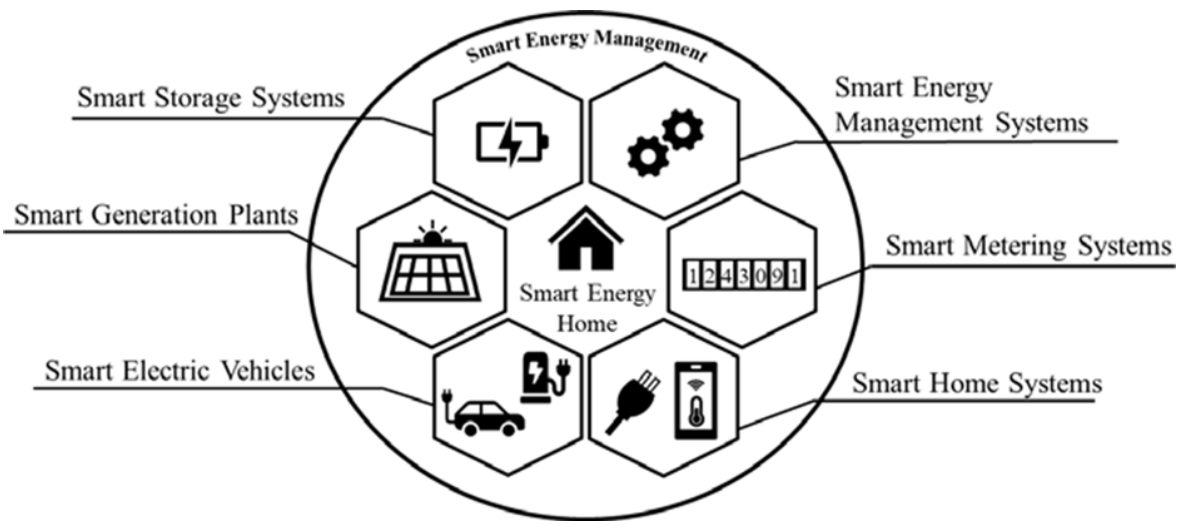

Fig. 2 Smart Energy Management for End Consumers. (Adapted from Paukstadt and Becker (2019))

Fig. 3 Smart Energy Products and Services. (Adapted from Paukstadt (2019))

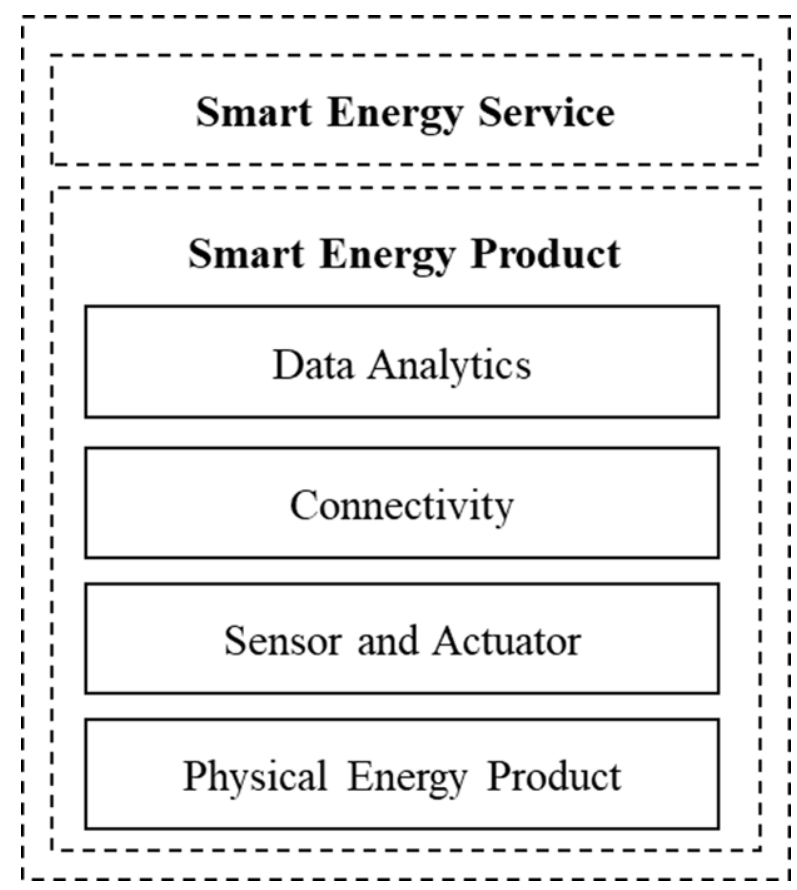

which constitute a smart energy product, smart energy services can be provided to the end user, e.g. in form of smart home or demandresponse applications.

\subsection{Smart Energy Services in the Light of the Service-Dominant Logic}

In the service science field, the S-D logic is very popular and becomes even more important with the emergence of smart products. The S-D logic states that a customer does not only acquire and use a good or service but participates in the value creation 
which is called co-creation in the service system. Value is co-created by using the product and service or being engaged with it (Beverungen et al. 2019; Vargo and Lusch 2004, 2008).

In contrast to traditional service environments, smart energy services engage the consumers more actively as resource integrators, since their user data is provided to the service provider (Turber et al. 2014; Vargo and Lusch 2004; Yoo et al. 2012). Moreover, not only service providers and consumers act as resource integrators but also smart energy products by networking themselves with other service providers, consumers, or products in the physical environment. The value co-creation by the smart energy product, the consumer and the provider enable new levels of values such as predictive maintenance based on the collected user, product, and context data (Beverungen et al. 2019; Porter and Heppelmann 2014). Smart energy services also facilitate more frequent customer interactions and monetization opportunities, for instance, by sending notifications or by providing new software features to the customer. Further, the tracked data from smart energy products, users and context facilitate new services (Hui 2014; Shomali and Pinkse 2016).

S-D logic assumes that services underlie all economic exchanges (Vargo and Lusch 2004, 2008). Following this, smart energy products are not offered in terms of selling goods but serve as platforms for services. As a result, smart energy services are an integrated aspect of smart energy products, blurring traditional distinctions between goods and services (Fleisch et al. 2014; Lusch and Nambisan 2015).

In addition, smart energy products are also smart product-service systems since they combine digital services and physical products as an entire solution to the customer (Goedkoop et al. 1999; Valencia et al. 2015). Since smart energy services require smart energy products, which in turn frequently contain supporting services, for example, the financing and installation of a smart PV system, these services are summarized in combination with smart energy products as smart energy service offerings as well (Paukstadt 2019). In Fig. 4 these smart offerings are named as "smart energy services in a broader sense" in contrast to smart services which are pure data-driven, digital services ("smart energy services in a narrow sense").

The value co-creation in the service system is also important due to the layered architecture of smart products that were introduced in the section before: By decoupling the single layers, smart energy services can be co-created. Different stakeholders can contribute on different layers of the smart product architecture, for instance, by offering sensors, actuators, and network assets as well as software for end users or data analytics services. Hence, the layers serve as sources of value cocreation by various participants in the ecosystem (Mejtoft 2011; Yoo et al. 2010). Beyond the use of a single smart energy product, more sophisticated smart energy services are enabled by the combination of different smart energy products, the data they deliver, and their controlling capabilities; thus increasing the value of the system for the customer (Porter and Heppelmann 2014).

In the following section, the S-D logic is applied to foster a service-oriented perspective on smart energy products. Moreover, the S-D logic highlights the importance of information as a central source for the value-creation and supports a better understanding of the new collaborative value creation logic between consumers, service providers and smart energy products. 


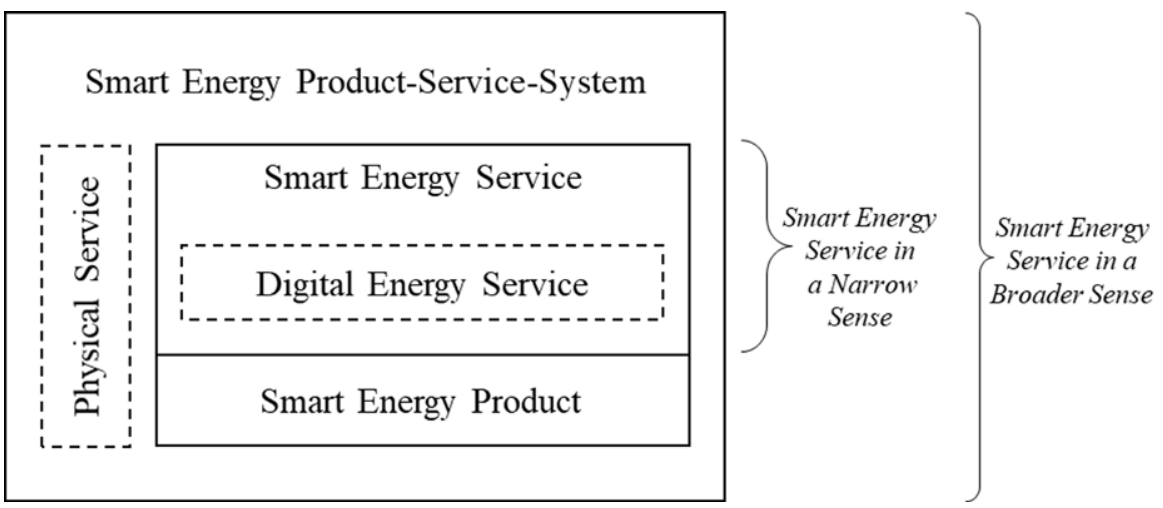

Fig. 4 Smart Energy Services in a Narrow and Broader Sense. (Adapted from Strobel et al. (2019))

For this paper, smart energy services are defined as services building on smart energy products (e.g., smart meters, thermostats, PV systems), and thus, making extensive use of data-based digital technologies to offer enhanced and new tailored (energy-related) values for customers. Furthermore, smart energy services can be offered as a pure digital service (e.g., monitoring of energy consumption) but can also be an embedded part of a smart energy product (e.g., a smart light bulb) and include optional (physical respectively human-based) supporting services (e.g., installation by a technician).

\section{Methodology}

To assess smart energy service design in a methodical fashion, this research applies design science research as an overall framework and combines this framework with the morphological design theory proposed by Zwicky (1948). Design science research is rooted in information systems research and enables one to build artifacts (e.g., models, concepts, software implementations) that are methodically grounded. According to design science literature (Hevner et al. 2004; Hevner 2007), the development of an artificial artifact such as a configuration box requires one to iteratively design and evaluate the artifact. The design science research cycle is depicted in Fig. 5. During the development cycle, the existing knowledge base should be considered and the (empirical) environment should be included. The use of the scientific knowledge base fosters rigorous design, whereas the application of the artifact in the environment increases the relevance (Hevner 2007).

As design science research does not prescribe a concrete method to develop an artifact of interest, concrete design activities are tied to a morphological analysis (Zwicky 1948, 1967). Morphology is the study of shapes and arrangements of elements of an object and how these parts can create a whole (Ritchey 2011, p. 8). A morphological analysis facilitates a structured development and presentation and a systematic comparison of entities of interest (Pousttchi and Hufenbach 2011). This type of analysis is used in particular to analyze complex problems to which formal 


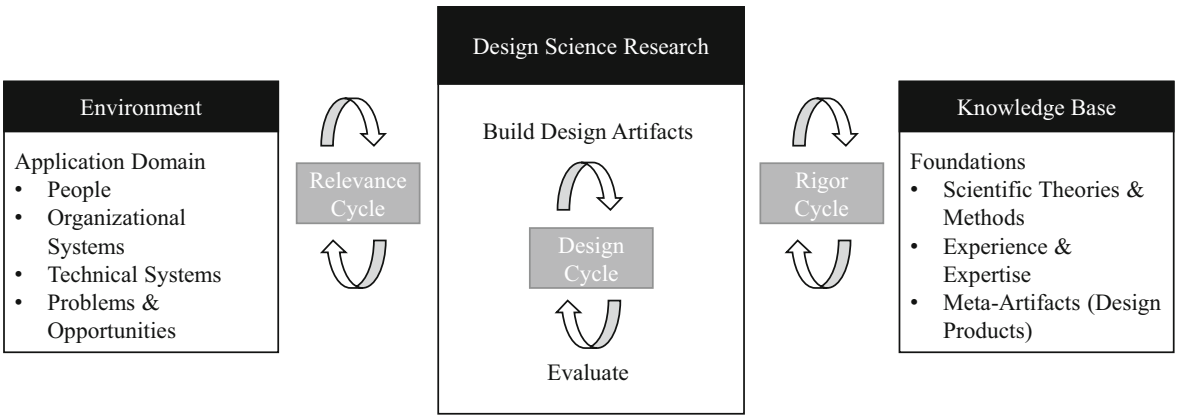

Fig. 5 Design Science Research Cycles. (Adapted from Hevner 2007)

methods, simulation and causal modeling cannot be applied (Ritchey 2011, p. 7). Thus, it enables a better understanding of how smart energy service innovation can be managed in an effective manner.

Although it is rooted in engineering and production industry, the morphological analysis has already been applied in the service and energy domain. For instance, in the related area of electric mobility, research has applied the technique to develop service offerings and corresponding business models for electric vehicles (EVs) (Kley et al. 2011). Moreover, Salah et al. (2017) have presented a morphological box for design options regarding energy services that are based on smart metering. Their analysis concentrates on energy services for end customers with a focus on energy quality criteria and pricing (e.g., flexible tariffs services).

In the first step of the development process, one compiles a comprehensive list of design dimensions that describe generic parameters of the system under study. In the second step, the researcher identifies concrete design options for each dimension. The information gathered is arranged in form of a matrix, the morphological box (Zwicky 1967), with the general dimensions as rows and the concrete design options as columns. By selecting design options for each dimension, one can develop solution instances.

Since the characteristics are not regarded as mutually disjunctive, a characteristic-based (morphologic) classification is intended (Fettke and Loos 2003). This is because smart service offerings are complex configurations, so more realistic design options should be enabled. For instance, one offering can provide multiple benefits to the customer, such as self-sufficiency and environmental advantages. This information would be lost with only mutually exclusive dimensions.

In this paper, the morphological design was informed by several sources, as depicted in Fig. 6. Fig. 6 also presents the iterative development approach. This approach always oscillates between the initial and new findings until an agreed upon, comprehensive and useful set of dimensions and characteristics are determined. Hence, the conceptualizations of the distinguishing parameters and elements are based on the author's creativity, reasoning and justificatory knowledge (Oberländer et al. 2018).

In the first step of this research, general literature on smart products and services was used to enhance the researcher's understanding of the problem area and 
Fig. 6 Sources for the Iterative Artifact Development

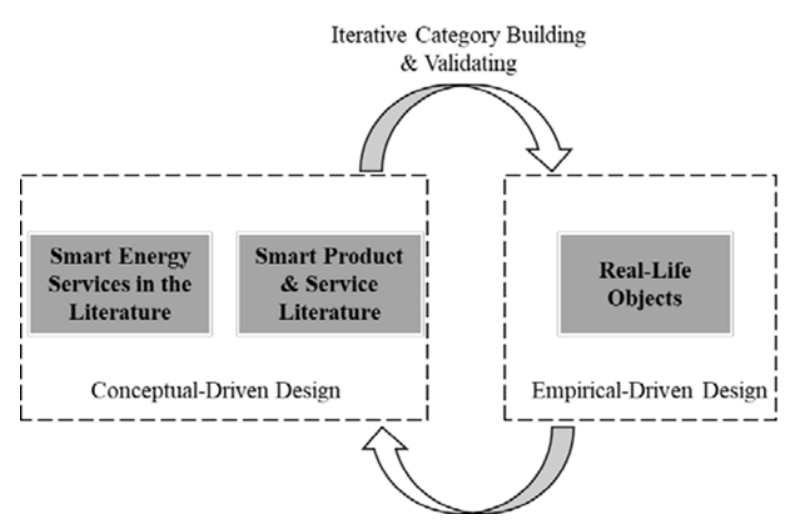

to determine suitable dimensions. For instance, the author's knowledge of existing service classifications in the field of smart services was useful when building a general framework with higher dimensions and specific general characteristics that were shared by all smart services, independent of their domains. Hence, the overall box was categorized into three subdimensions: smart energy services, smart products and monetization (Paukstadt et al. 2019b). The smart energy service and smart product layers support the S-D logic perspective, and thus the interwoven nature of smart services and products. The monetization perspective was included, since energy companies often face problems to charge smart (energy) services (Richter and Pollitt 2018; Wünderlich et al. 2015). As smart energy services enable mutual benefits for the service provider and the consumer in the value-co-creation (Beverungen et al. 2019), the monetization layer also concentrates on the local usefulness of the service provider while, for instance, the consumer key value addresses the customer benefit. The use of the S-D logic further emphasizes the co-creation of value in the smart energy service layer. The co-creation is particularly important in the energy domain in which prosumers and consumers with provision flexibility actively engage in smart energy services (Wünderlich et al. 2015).

Second, the extant literature on smart energy services in Sect. 4 was reviewed to identify the most important smart energy services and to derive initial dimensions and characteristics that are shared by similar smart energy offerings.

Furthermore, 16 smart energy services from companies were analyzed to identify important characteristics that could have been missed by the literature review or that support the literature-based conceptualization (Table 2 in the Appendix). During this step, the category smart energy technologies included was introduced with the following characteristics: consumption-related, production-related, storage-related, integration-related, no smart product included. These characteristics indicate if the offering consists only of one application area, such as consumption-related devices like smart home and energy monitoring equipment, or if the offering is bundled with production and storage units to improve overall energy management. The indepth analysis of real-life cases also uncovered the need to further specify the monetization layer. Thus, the dimension indirect revenues was added. Some smart energy services, such as smart meters or demand response, are, in a sense, free for 
consumers. However, these consumers pay with their energy and digital resources, with which the service providers can make money by selling energy resources to third parties or achieving internal cost optimizations (e.g., ConEdison Smart Meter, OhmConnect). Although the market analysis overlooked some characteristics that were identified as relevant in the literature (e.g., data as a value and resource itself), these characteristics were considered in the morphological box in order to provide a future-oriented conceptualization.

To identify the real-life services, websites of companies offering smart energy services for end consumers were accessed. The services were identified by a Google search with predefined keywords (e.g., "smart energy service" or "smart grid service"). The objective was to identify a wide range of different smart energy services to cover as many characteristics as possible. The market offerings were analyzed as if they were offered by the companies. For instance, if a company offered a smart home bundle consisting of several smart plugs and lighting, actuaries and sensors, this bundle was analyzed as one offering.

Following the examples in the scientific literature (e.g., Oberländer et al. 2018), the final morphological box was evaluated by classifying a larger number of real-life cases (i.e., assigning the single elements of the smart energy services to each of the morphological box's characteristics). The classification of real-life cases assisted in verifying whether and how evidently and instinctively the real-life services could be assigned to suitable dimensions and characteristics (Oberländer et al. 2018). After this process, 51 smart energy services were classified and the frequency of the single characteristics' occurrences were analyzed in Sect. 6.1. The 51 services are listed in Table 2 in the Appendix.

The use of various sources from the literature and empirical data finally led to the development of a future-oriented smart energy service classification. Only characteristics were included that are relevant to the energy sector and for which evidence was provided by the literature or empirical cases. For instance, no evidence was found for the pricing mode "pay as you want", and there is no plausible indication that this mode may feature prominently in the future; therefore, it was not included. Sect. 6 describes each dimension and characteristic of the morphological box. This explanation is also accompanied by justificatory references. The next section presents the key findings from the literature and used to extract the characteristics for the smart energy service classification.

\section{Smart Energy Service Characteristics Derived from Literature}

This section revisits existing literature related to different smart energy services. Based on a comprehensive review of the literature conduced in former research, the smart energy services were grouped into superior service types, which are described in the following. The services are illustrated along the energy value chain in Fig. 7. By extracting the essential components described for the service types, single characteristics of smart energy services for the morphological box were derived. For example, flexibility was a central characteristic, as was the differentiation between 


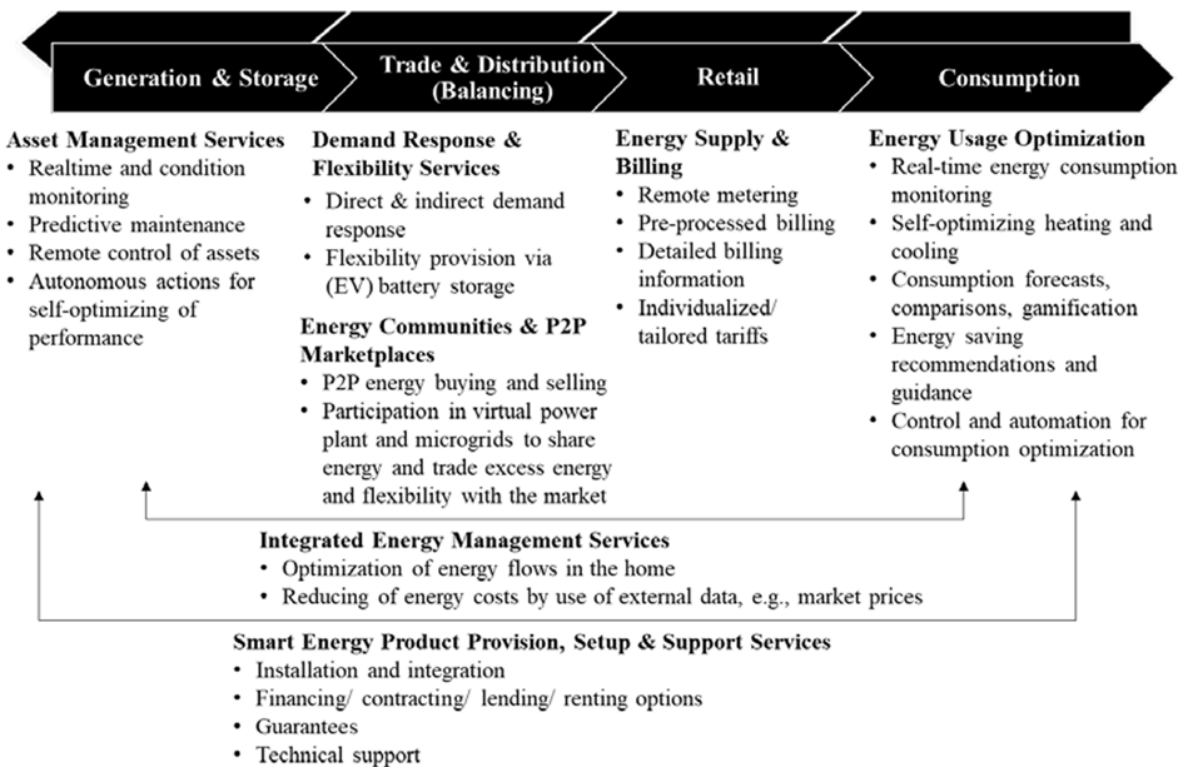

Fig. 7 Overview on Smart Energy Service Types Along the Value Chain

consumers, prosumers, communities and the nature of the offerings, the latter which can be product- or service-oriented, with the ownership changing among the actors.

In the following, we will explain each smart energy services type. For the sequence of the description, we weighted the service types according to their feasibility and possible market penetration and depicted this in a two-by-two matrix (Fig. 8).

We also accompanied this by adding some exemplary services from the market analysis. Since smart energy offerings on the market often consist of several smart energy services identified in the literature review, the services from the market analysis were assigned according to their main focus. In this regard, setup and supports services for smart energy products, as well as energy usage optimization services have a high market penetration and feasibility. Lower market penetration with low feasibility was observed for flexibility services in terms of the co-provision of EV storage (e.g., using the storage of EVs to stabilize the grid). Currently, this stabilization service is found primarily in pilot projects, such as OVO Energy, which uses a vehicle-to-grid charger that is funded by the government. OVO Energy allows consumers to participate in trials. Low market penetration but higher feasibility can be seen in services related to innovative energy supply and billing, demand response, energy communities and P2P energy marketplaces as well as asset management services. This initial assessment regarding the market penetration and feasibility is further supported by the systematic classification of 51 smart energy services in the morphological box in Sect. 6.1.

Smart Energy Product Provision, Setup, and Support Services Although these services are not smart in a narrow view, smart energy products must be installed at a customer site first before the customer can use smart energy services. Basic services 
Fig. 8 Feasibility and Market Penetration of Smart Energy Services

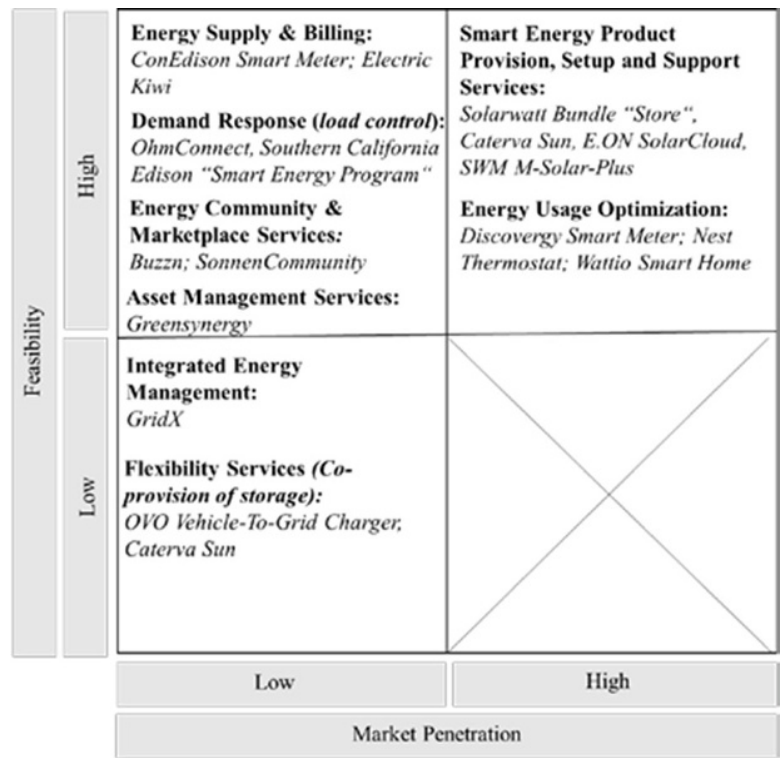

consist of the sale, rent or lease of smart energy products such as smart metering devices, smart home systems, microgeneration units, storage systems, and electric vehicle charging infrastructures, for example, via an online marketplace. Additional supporting services can have different contract depths that involve consultation, installation or integration, operation, maintenance, financing, and technical support during usage of the smart energy products (Hamwi and Lizarralde 2017; Helms 2016; Richter and Pollitt 2018). A special type of storage is cloud storage. With cloud storage, a consumer does not need to buy and own a physical storage unit but can use a virtual storage unit for a usage fee (Liu et al. 2017).

Energy Usage Optimization This category consists of smart energy services that use the data from smart metering and other smart appliances for monitoring energy use. The resulting services can offer a wide range of real-time consumption information, feedback, and advice. The monitoring and visualization of energy consumption can assist consumers in saving energy by identifying inefficient behavior and large energy consuming appliances. When combined with a microgeneration unit such as a PV system, a service can also monitor and visualize an individual's production level (Geelen et al. 2013; Goldbach et al. 2018). Other services include appliancelevel energy monitoring, alarm notifications regarding irregular consumption, historical comparison, forecasting, simulation or the comparison of energy consumption with others (Geelen et al. 2013; Goldbach et al. 2018; Heiskanen and Matschoss 2016). Gamified energy consumption information and serious games where participants have to achieve challenges, earn points and can compete with others can also be combined with social media services (e.g., through social comparison) (Camarinha-Matos 2016; Geelen et al. 2012; Hamwi et al. 2016). The energy usage can 
be also optimized through personalized, real-time information in combination with human advice (Heiskanen and Matschoss 2016; Richter and Pollitt 2018).

Instead of only monitoring energy use, control and automation services serve as a more sophisticated way to optimize energy usage by enabling consumers to control smart energy products remotely (Geelen et al. 2013; Richter and Pollitt 2018). Specific smart energy services allow their user to configure rules and time settings (Ford et al. 2017). By using artificial intelligence, self-learning autonomous systems can optimize energy consumption without requiring action from the user (Byun et al. 2011).

Energy Supply and Billing Services "Energy supply as a service" is the guarantee to supply a specific level of heat, lighting, cooling, which can be facilitated by the collected data (e.g., from smart meter) (Fox-Penner 2009; Giordano and Fulli 2012). In this regard, Pitì et al. (2017) have stated that contracts can be customized based on the collected measurements. Furthermore, remote and real-time metering can offer current, (for example, monthly), accurate and informative billing based on smart metering data. Also the need for a technician to come to read the meter manually is obsolete when using smart metering (Shomali and Pinkse 2016).

Demand Response and Flexibility Services Demand response services aim to induce behavioral changes to change the load curve for a short period to times when renewable energy is available or to hinder peak loads, and thus help stabilize the grid (Goldbach et al. 2018). Demand response services can comprise incentives that are given to consumers to enable the utility to shut off a household's appliances. Other demand response services send signals to the consumers, who respond independently to shift their loads in exchange for financial compensation. Flexible prices (real-time prices, time-of-use pricing et cetera) vary over short periods and can be further used in demand response programs (Goldbach et al. 2018; Niesten and Alkemade 2016; Salah et al. 2017). For EVs, grid-to-vehicle services are offered that let the consumer charge their EV and pay for the consumed electricity. Smart charging can make use of price differences due to flexible tariffs, and thus can lower charging costs (Bhatti and Danilovic 2018; Niesten and Alkemade 2016). As EVs can consume energy but also provide saved energy, they can be also used for demand response services in which the EV charging process is shifted to times of low energy demand or interrupted due to grid instability (Weiller and Neely 2014). The EV battery can also be used as a flexibility source for the overall smart grid by using a fleet of plugged-in EVs as power sources for the ancillary services market and as energy reserves for wholesale markets (vehicle-to-grid) (Niesten and Alkemade 2016).

Energy Community and Marketplace Services Smart energy services can also support the exchange of information and sharing of energy resources such as microgeneration units and storage among a group of consumers. Consumers can contribute financially or with capacities likes energy storage and PV systems in a community. The generated energy is organized intelligently to coordinate supply and demand within the community (Geelen et al. 2013; Hyytinen and Toivonen 2015). Typical forms of energy communities are microgrids and virtual power plants. Microgrid are 
local clusters of microgeneration units, storage systems, and loads acting as one unit and can be operated in isolation from the main grid. In contrast to a microgrid the constituent parts (e.g., microgeneration, storage, and load) of a virtual power plant can be distributed and are virtually coupled (Koirala et al. 2016; Lasseter 2002; Martin-Martínez et al. 2016). Both community forms can sell their excess energy by bundling the produced energy of distributed small generation plants and marketing the aggregated energy (Helms 2016; Koirala et al. 2016; Martin-Martínez et al. 2016).

Customers can be further enabled to sell their energy to other parties through a broker such as an energy company (Rodríguez-Molina et al. 2016). One can trade energy directly on online marketplaces by employing automated agents that act for the customers and consider, for example, the user behavior, the calendar or statistical information (Karnouskos 2011; Salah et al. 2017; Vytelingum et al. 2010). On P2P marketplaces, prosumers can buy and sell their self-produced energy independently to other consumers via platforms (Löbbe and Hackbarth 2017).

Smart Energy Asset Management During system operation, the provider of the smart energy products can offer remote and predictive maintenance and security services, for example, by monitoring the status of the appliances remotely, deploying upgrades to the firmware, detecting potential failures or proactively planning maintenance actions (Karnouskos 2013; Porter and Heppelmann 2014). For instance, to enable intelligent fraud detection and risk management, the condition of the smart energy products is assessed and predicted based on historical and real-time data $\mathrm{Wu}$ et al. 2012). Building upon the data analysis, the system can detect risks and take actions such as switching off assets or providing fault alarm services (Byun et al. 2011; Wu et al. 2012).

Integrated Energy Management An integrated energy management builds upon monitoring and controlling capabilities and intelligently manages and optimizes the consumption, storage and production autonomously, for example, in terms of the feed-in of excess power and additional energy demands from the grid (Geelen et al. 2013; Porter and Heppelmann 2014). These sophisticated services connect numerous production- and consumption-oriented smart energy technologies (e.g., EV, PV systems, storage and household appliances) and consider diverse context, usage and external data (e.g., tariffs, user preferences and weather conditions) (Byun et al. 2011; Pitì et al. 2017). For instance, vehicle-to-home describes the use of EV storage to save energy, and thus an EV battery can be used within an energy management system (Weiller and Neely 2014). Integrated energy management occurs primarily on a household level to optimize the energy flow within one's "smart energy home," but it can also contribute to the overall grid.

\section{Morphological Box}

Fig. 9 presents the morphological box that facilitates a systematic identification of design options for consumer-oriented smart energy services based on smart energy 
Fig. 9 Morphological Design Options for Smart Energy Services ( $M E$ mutual exclusive, i.e., only one parameter is selected)

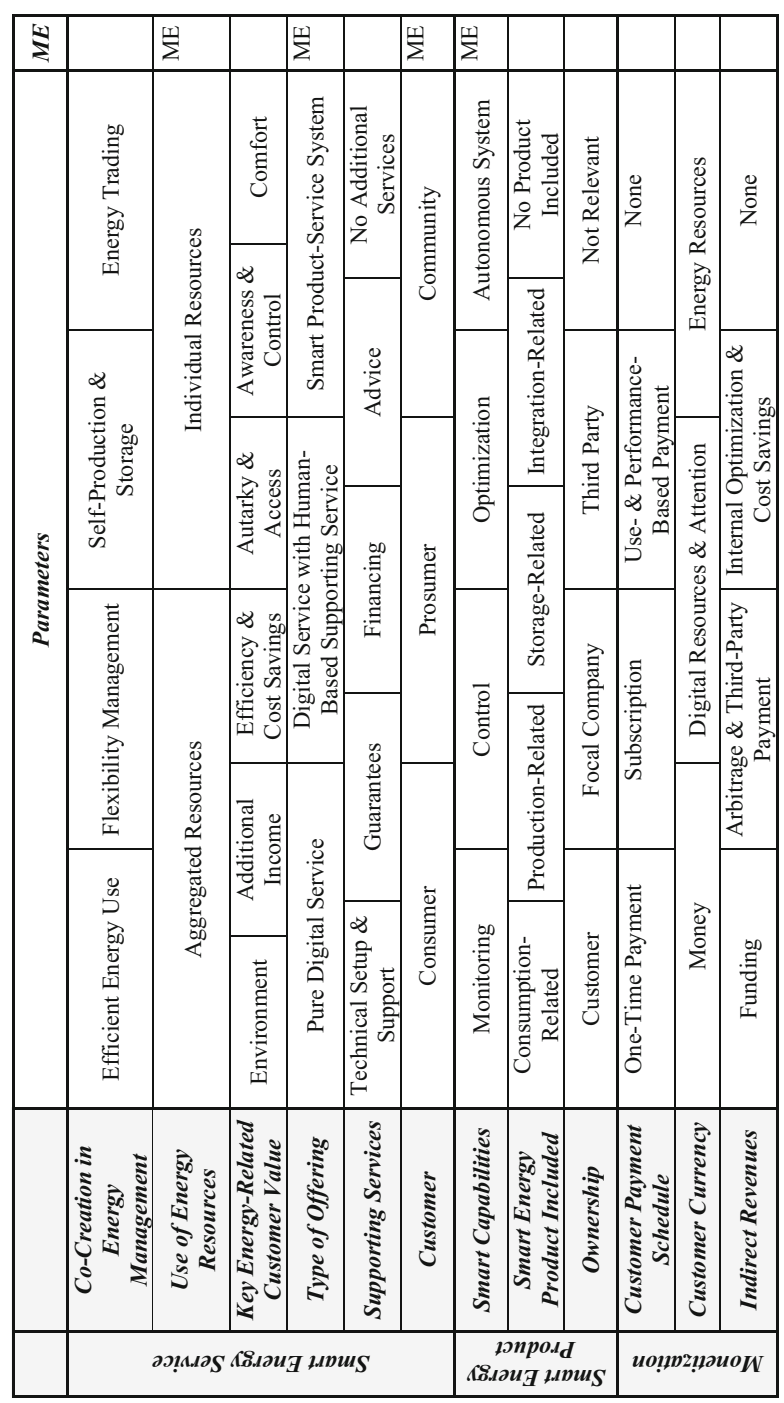

products. The design is grouped into the three overarching categories: smart energy service, smart energy product and monetization. In the following section, the dimensions and their corresponding design options are described.

\subsection{Smart Energy Service}

Co-Creation in Energy Management Since consumers are actively engaged in the energy value chain functions and strongly co-create value together with the service provider and the smart products, co-creation in energy management is separated into efficient energy use, flexibility management, self-production \& storage, and en- 
ergy trading (Geelen et al. 2013). The dimension co-creation in energy management concentrates on the main energy function, for instance, ConEdison's Smart Charge Upgrade supports mainly flexibility management through a time-of-use tariff.

Smart energy services that fall under the efficient energy use function mainly involve services that help to reduce energy consumption (e.g., energy monitoring or control options via smart thermostats) (Geelen et al. 2013; Hamwi and Lizarralde 2017). Moreover, specific energy supply tariffs and "energy-as-a-service" offerings - for example, "supply of warmth", "supply of light" or room specific energy tariffs based on smart meter data-are placed in this category, since an individual's supply of energy must be consumed (Fox-Penner 2009; Giordano and Fulli 2012), which leads to value-in-use (Vargo and Lusch 2004). Furthermore, consumption can be more efficient due to the detailed energy data and control.

In flexibility management, flexibility is defined as the modification of supply or demand in response to an external signal (price signal or activation) with the aim of providing a service in an energy system (Bundesnetzagentur 2019). As highlighted in Sect. 4, customers can contribute to provide different forms of flexibility, for example, through demand response. Electric vehicle batteries can also provide vehicle-to-grid services (Weiller and Neely 2014). The review of the real-life examples also indicated that companies like Caterva let customers participate financially by providing their battery storage as a flexibility resource. Some home energy storage or EV chargers can also make use of price difference due to time-of-use tariffs. Some smart storage devices buy stored energy when it costs less, (e.g., during the daytime) and sell it in the evening when energy prices are high (Rodríguez-Molina et al. 2016) (e.g., Sunverge One stores energy when it is inexpensive).

The aforementioned examples provide flexibility to the macro-grid which helps to balance the overall grid. The household-level balancing of supply and demand with, for example, an energy management system, PV system or energy devices, is classified in the morphological box as efficient energy use and self-production \& storage. Energy communities are similarly classified as self-production \& storage and efficient energy use, since they balance supply and demand within a community.

Smart energy services can also control and manage energy production from, for instance, local PV systems, so that the energy is feed into the grid when the prices are high (Geelen et al. 2013). In general, EV charging is regarded as the co-creation of self-production \& storage, since energy consumption and storage are time separated. Smart energy services for community management can facilitate energy production, since they facilitate the local production of electricity by sharing and aggregating resources (Hamwi and Lizarralde 2017; Hyytinen and Toivonen 2015).

Energy trading is the purchase and sale of energy produced by customers to other customers or energy providers, and it serves as another form of co-creation. In this situation, the signing of an energy contract would not be regarded as energy trading, but as efficient energy use. The feed-in of customers-produced energy is one simple form of energy trading. Another, more sophisticated form of energy trading is $\mathrm{P} 2 \mathrm{P}$ energy marketplaces (Geelen et al. 2013; Löbbe and Hackbarth 2017).

Aggregation Some smart energy services co-create value by forming a network of customers and aggregating their energy resources (Martin-Martínez et al. 2016). 
Examples of aggregation are demand response services, where a service provider can act as an aggregator for private households loads, as well as storage and generation units (Niesten and Alkemade 2016). Aggregation is also employed by vehicle-to-grid or grid-to-vehicle services and community services such as microgrids and virtual power plants (Geelen et al. 2013; Hamwi and Lizarralde 2017; Koirala et al. 2016).

Individual resources involve smart meter reading and billing (Apajalahti et al. 2015) as well as vehicle-to-home services (Weiller and Neely 2014).

If one offering indicated the use of aggregated resources as part of its core offering (e.g., OhmConnect) or even only as a small extra service (e.g., Caterva's offering), it was classified as an aggregation, otherwise it was classified as individual resources. Hence this dimension is mutually exclusive.

Key Energy-Related Customer Value The customer value describes the value(s) provided through bundles of products and services that are offered to a specific customer segment (Osterwalder and Pigneur 2010). To ensure the informative value of this dimension, it is important to focus on the key value instead of instantiating all possible relevant (side) values. Hence, the value environment (Niesten and Alkemade 2016) is only considered relevant if there is a direct environmental benefit offered by the service. For instance, a green energy tariff would be an example for promoting the supporting the environment as key value.

Financial benefits can be efficiency \& cost savings and additional income. Cost savings are often a result of energy savings. For instance, energy monitoring, controlling and automation services enhance energy efficiency, and thus lead to energy and cost savings (Byun et al. 2011; Richter and Pollitt 2018). Furthermore, flexible tariffs can help private households lower electricity bills (Hamwi and Lizarralde 2017; Niesten and Alkemade 2016). To gain an extra income, customers can cocreate by providing energy and flexibility resources to a service provider. The extra income in exchange for energy and flexibility can be achieved, for instance, through incentives in direct load control programs and vehicle-to-grid services or by selling own produced energy (Geelen et al. 2013; Weiller and Neely 2014).

Other services enable autarky \& access to energy resources. Some customers aim to be self-sufficient and independent of large energy providers by producing their own energy (Koirala et al. 2016; Löbbe and Hackbarth 2017). However, an individual does not need to possess microgeneration technology to use decentralized energy. For instance, in energy communities, microgeneration units and storage are shared within the community, and thus lower financial barriers offer more households the option to participate in the renewable energy system (Hamwi and Lizarralde 2017; Zhang 2016).

Smart energy products provide consumers with more information on their energy usage, which can lead to higher perceived awareness through transparency and control over their energy consumption. Perceived control can be further achieved by the remote control of devices (Niesten and Alkemade 2016).

As the focus of this research is on energy-related values, the morphological box does not consider security surveillance in smart homes, but it does consider comfort, as this factor is often an important aspect of energy saving measures or demand response programs. Through the use of controlling and automation services, 
the energy processes can be managed without user action, and thus can enhance comfort (Helms 2016; Niesten and Alkemade 2016).

Offering The focal offering can consist of a digital service such as a smartphone application (app) (e.g., digital add-ons for premium analyses in Innogy's smart home app). Since the flow of energy is regarded as an inherent part of all offerings, a digital service could also be a flexible tariff that could be monitored via an app (Paukstadt et al. 2019a).

Beyond a pure digital service, the offering could further comprise physical respectively human-based service components. For instance, the digital component could be a predictive maintenance service for a microgeneration unit and the physical service could comprise a technician who is notified of repair tasks by the system. The full bundle of smart energy products, digital and optional physical services is considered a smart product-service system (Mittag et al. 2018).

Supporting Services Due to several adoption barriers of smart energy technologies and services, such as the complexity of smart energy systems and high upfront costs, researchers have recommended that providers offer additional supporting services (Kahma and Matschoss 2017).

Due to the complexity of smart energy products, technical setup and support services are often considered necessary (Richter and Pollitt 2018). Kahma and Matschoss (2017) have suggested bundling smart energy services and products in packages and offering financing options for the technologies as well as regulation guarantees, such as free access to an electricity network and a specific price for feed-in electricity; these elements can be further complemented by reliable advice. Financing can help potential customers overcome high upfront costs, whereas guarantees and advice can support building users' trust and the credibility of real energy saving potential. Advice can be given in person or via chatbots or other digital forms. It can further consist of legal advice, advice regarding funding as well as presales product consulting (e.g., ecobee). Sometimes no additional service is required or offered.

Customer In the residential customer segment, customers can be categorized as consumers, prosumers and communities (Paukstadt 2019a). Consumers only consume energy, and therefore use services like monitoring and controlling energy consumption. A consumer who both produces and consumes energy is called a prosumer (Karnouskos 2011). Another customer type is a community, which is a group of prosumers and eventually consumers who form integrated energy systems, for instance, in the form of a microgrid or virtual power plant (Hamwi and Lizarralde 2017; Koirala et al. 2016).

\subsection{Smart Energy Product}

Capabilities Smart energy products can serve several functions which smart energy services can then build upon. The capabilities of smart energy products range from monitoring, control and optimization to autonomous actions (Porter and Hep- 
pelmann 2014). For instance, smart meters provide information and monitoring functions for energy consumption information (Kahma and Matschoss 2017; Richter and Pollitt 2018).

Smart household appliances enable controlling functions such as remotely switching appliances on or off or using rules. Through the use of rules and other configuration options, controlling enables the personalization of smart energy products (Ford et al. 2017; Porter and Heppelmann 2014). Demand response services can also leverage the control functions of household appliances when generating plans to shift energy consumption to optimal times (Hyytinen and Toivonen 2015; Niesten and Alkemade 2016).

Optimization uses product monitoring and environmental data to perform analyses and execute actions. Smart energy products can also act completely autonomously. For example, a community service could use microgeneration units and the storage of several households to autonomously optimize supply and demand by considering several conditions (e.g., electricity prices, weather and energy forecasts) (Byun et al. 2011; Kahma and Matschoss 2017; Porter and Heppelmann 2014). In this case, one or more smart energy products perform actions without human support, and they not only provide suggestions for decision making but also perform the actions on their own and eventually can coordinate with other connected smart products (Porter and Heppelmann 2014).

Smart Energy Product Included The included smart energy product can be consumption-related, as with smart metering and home devices. Smart home devices include smart plugs, separate actuaries and sensors; these components are often sold together as smart home bundles. Moreover, smart heating, smart heat pumps and air conditioners are considered smart home devices, since they consume household energy the same way a traditional appliance (such as a fridge) would.

However, smart meters are also required to monitor energy production; thus, they can also be incorporated into PV systems in which they are regarded as production-related products. Furthermore, production-related products include PV systems, miniature wind turbines and combined heat and power, whereas storagerelated products are EV and household batteries.

Integration-related products are hubs that connect several different application areas. Furthermore, an offering could not include any smart product (e.g., Innogy's smart home smartphone add-on).

Product Ownership As services become even more important with the rise of the Internet of Things, the classic paradigm of customer ownership of products can shift to be more usage- and performance-based, with the focal company or a third party as the owner (Fleisch et al. 2014).

Renting devices for energy visualization from the focal company would be rather use-oriented, particularly if the rent were to depend on the actual usage (i.e., pay per use) (Hamwi et al. 2016).

For some smart energy services, the corresponding smart energy product ownership is not relevant because the product is already available at the customer site. For 
instance, the customer may buy a digital service for an existing smart home, such as Innogy's smart home smartphone add-on.

\subsection{Monetization}

Customer Payment Schedule A one-time payment is the sale of assets or services. Subscription-based payments are regular time-based payments made regardless of usage (Gimpel et al. 2017). Beyond the basic sale of a smart energy product, smart energy products facilitate and improve use-and performance-based payment modes (Hui 2014; Porter and Heppelmann 2014). The use- and performance-based payment modes are quite common in the energy sector with energy plans that consist of a fixed subscription and a flexible rate that depends on the energy consumption. Use-and performance-based payments are also used for EV charging. If flexible prices are strategically exploited, they can be also regarded as a form of pay per performance, since a customer is rewarded for "grid-friendly" energy consumption, and the service provider also profits due to lower grid-related costs.

Services may also not include a payment mode (i.e., none), for example, due to non-monetary value for the service provider, such as the use of secondary data, tailored pricing models or higher levels of efficiency (Beverungen et al. 2019). Regarding smart energy, there are digital services that are provided for free, such as smart home apps and flexibility-related services (e.g., the OhmConnect app).

Financing is not considered separately if it is only offered as a second option to a one-time payment. Moreover, different financing forms, such as leasing or renting, can be represented in the morphological box by considering the ownership and using the subscription parameter.

User Currency Apart from money, customers can also pay with digital resources such as energy data (Shomali and Pinkse 2016), digital tokens ${ }^{1}$ or attention to (digital) advertisements (Gimpel et al. 2017) provided through digital devices (e.g., purchase recommendations based on smart meter data). For instance, the company sunbeam $^{2}$ offers an end-customer portal for PV systems that offers up- and crossselling options based on the collected data. Data are becoming more valuable, since data can be used for marketing, sold to other parties or used for grid optimization (e.g., better load predictions) (Bischoff et al. 2017; Gimpel et al. 2017; Strüker et al. 2011).

Additionally, the user can pay with energy resources, for instance, with their own produced energy or flexibility (e.g., sonnenCommunity and OhmConnect). Energy resources as well as digital resources \& attention are regarded as another form of currency besides money.

\footnotetext{
1 The empirical review revealed several ambitions in this direction, such as Grünstromjeton (https://www. energieagentur.nrw/content/anlagen/SEV-Gruenstromjetons_final.pdf; accessed 05 August 2019) and energimine (https://energimine.com/energitoken/; accessed 05 August 2019).

2 https://sunbeam-communications.com/leistungen/endkundenportal-pv/ (accessed 05 August 2019).
} 
Indirect Revenues Some smart energy services are publicly funded, for instance, the OVO Energy EV Charger. The morphological box considers funding with the dimension indirect revenues. Although it is often the customer, not the service provider, who receives funding, this funding increases the service provider's sales and sales prices. Arbitrage, which capitalizes on energy price differences by buying customer energy and selling it to the energy market, is also regarded as a third-party payment (Weiller and Neely 2014). OhmConnect offers residential consumers additional income through participation in a demand response program provided via a smartphone app. The app is provided for free and the service does not cost the consumer money. OhmConnect makes money through arbitrages by selling flexibility to the market. The sale of data is another example of a third-party payment. Moreover, internal optimizations and cost savings are additional forms of indirect revenue (Beverungen et al. 2019).

\section{Application and Empirical Illustration}

In the last stage of this research, a total of 51 commercial smart energy services were classified in the final morphological box to gain insight into the occurrences of the single service characteristics. The sample of real-life objects and their classifications are also listed in the Appendix. An exemplary classification of four empirical cases with corresponding descriptions is provided in the next section.

\subsection{Application of the Morphological Box to Real-Life Objects}

The classification of empirical objects not only validated the applicability of the morphological box with real-cases but also provided insight into the frequency of specific characteristics covered by the commercial offerings, as is depicted in Fig. 10. The analysis of occurrences revealed the following main observations:

For the dimension co-creation in energy management, most of the services focus on efficient energy use (71\%) and self-production and storage (53\%).

Furthermore, $76 \%$ of the services use individual energy resources. Only $24 \%$ make use of aggregated energy resources, for example, through flexibility provision or energy communities.

The key energy-related customer values advertised on the company websites concentrate on efficiency \& cost savings (76\%). Only $18 \%$ of the offerings explicitly list sustainable environment as a value. Comfort is an important factor for $43 \%$ of the smart energy services.

The type of offering is predominantly product-based: $69 \%$ of the offerings are smart-product-service systems consisting of a smart product, digital service and eventually supporting services. Digital services in combination with human-based supporting services are not covered at all by the classified examples.

If additional supporting services are offered, they are mainly technical setup \& support services (43\%). Of all the offerings, $47 \%$ do not offer supporting services.

The main customer group addressed is consumers (61\%), whereas community offerings are quite rare (10\%). 
Fig. 10 Frequency Analysis of the Characteristics of Smart Energy Services

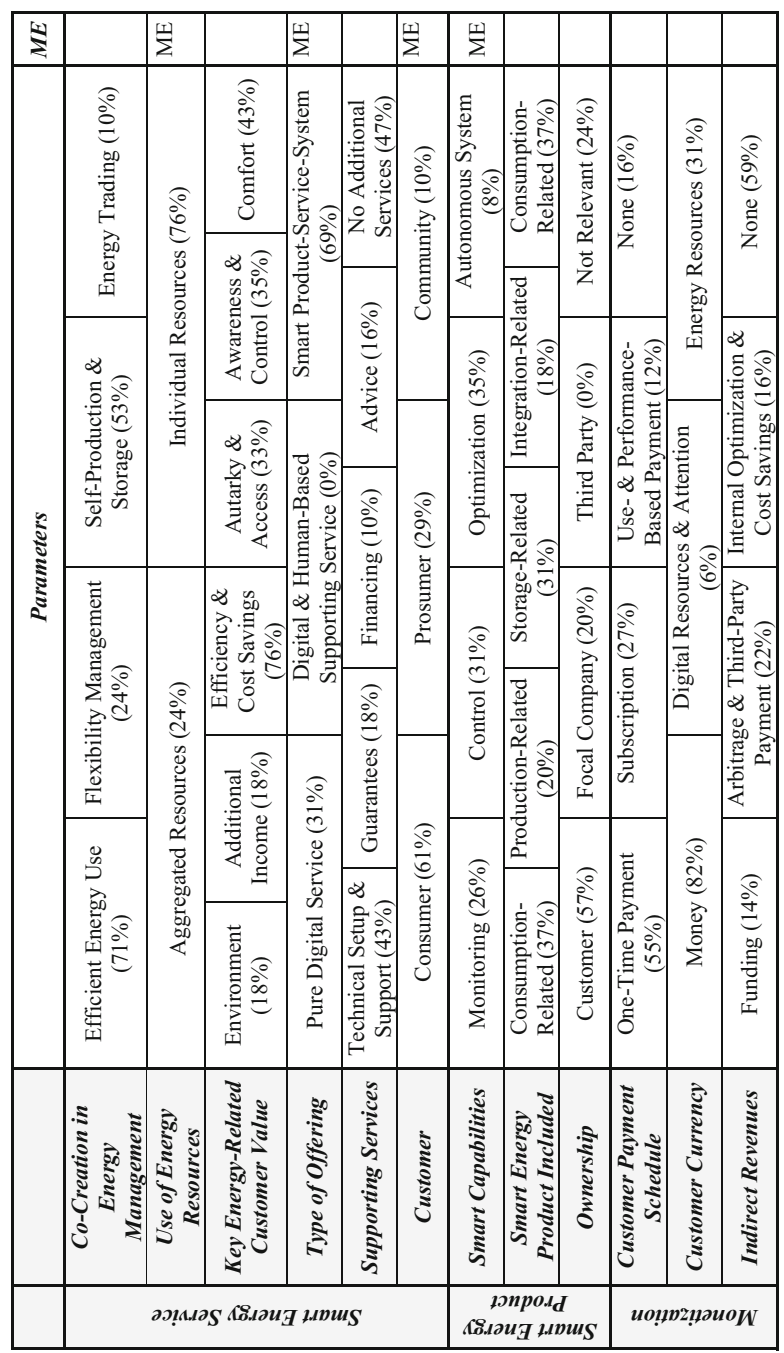

If the ownership of the provided smart product is relevant, in $57 \%$ of the cases the product belongs to the customer, whereas in $20 \%$ the focal company is the owner.

The capabilities of the smart products are quite balanced between information and monitoring (25\%), controlling (31\%), optimization (35\%). However, only $8 \%$ of the offerings act autonomously based on artificial intelligence and are highly interconnected with other products.

Most of the smart energy products included in the offering are consumptionrelated $(37 \%)$, particularly smart energy monitoring and smart home devices. There are also pure digital offerings, with no smart product included (27\%). One specific classification is two cloud storage offerings that are regarded as pure digital offerings 
with a storage-related smart energy product included, even though the smart energy storage is owned by the focal company.

One-time payments, for example, the basic sale of smart energy products, are widely applied by $55 \%$ of the offerings. Only some of the offerings employ usebased \& performance-based payments (12\%). Eight offerings (16\%) are offered at no cost to the customers because the provider earns money through third-party payments or internal optimization.

Forty-two smart energy services (82\%) accept monetary payment. There were only four clear indications of companies that use digital resources, such as user data, to capture value (8\%). Of the offerings, $31 \%$ derive all or some of their value from energy resources.

Although the customer is generally the direct revenue stream, in some cases indirect revenue is also generated via funding (14\%) or via arbitrage \& third-party payments (22\%). However, most of the services (59\%) do not appear to have indirect revenue streams.

\subsection{Empirical Illustration}

In this subsection, the applicability of the morphological box is demonstrated by analyzing four empirical cases: E.ON SolarCloud, which is a cloud storage offering;; a demand response program based on smart thermostats by Southern California Edison (SCE) and an intelligent energy manager by GridX (Table 1).

E.ON SolarCloud The SolarCloud by E.ON provides virtual storage for solar power without the need to own physical storage. The cloud storage primarily addresses prosumers who have a PV system but no physical storage to enhance their autarky. Since this offering reduces the barrier of high upfront costs, it also facilitates access to battery storage for households who do not want to buy expensive storage. They can save any surplus energy produced by the PV system in the cloud and recover it later, when it is needed, in exchange for a monthly fee (subscription). The service requires controlling capabilities, since the user must be able to control the storage process. The cloud status and credit can be displayed in an app, which is included in the offering, making it a pure digital offering.

SCE Smart Energy Program The Smart Energy Program by SCE is a demand response program with direct load control by the utility. Hence, the co-creation in energy management is flexibility management. The utility is allowed to control the smart thermostats of households to reduce peak loads. By participating, the customers can earn extra money by offering their energy resources in the form of flexible loads. Table 1 analyzes the case in which the customer already owns a smart thermostat; here, the Smart Energy Program is a pure digital service with no smart product included in the offering. The customer does not pay with money for the participation but provides flexibility that enables efficiency and cost savings for the energy provider. The program is further funded by the government. 
Table 1 Examples for the Classification of Real-Life Objects

\begin{tabular}{|c|c|c|c|c|}
\hline & & E.ON SolarCloud & $\begin{array}{l}\text { SCE Smart Energy } \\
\text { Program }\end{array}$ & $\begin{array}{l}\text { GridBox Energy } \\
\text { Manager }\end{array}$ \\
\hline \multirow[t]{6}{*}{$\begin{array}{l}\text { Smart } \\
\text { Energy } \\
\text { Service }\end{array}$} & $\begin{array}{l}\text { Co-Creation in En- } \\
\text { ergy Management }\end{array}$ & $\begin{array}{l}\text { Self-Production \& } \\
\text { Storage }\end{array}$ & $\begin{array}{l}\text { Flexibility Man- } \\
\text { agement }\end{array}$ & $\begin{array}{l}\text { Efficient Energy } \\
\text { Use, Self-Produc- } \\
\text { tion \& Storage }\end{array}$ \\
\hline & $\begin{array}{l}\text { Use of Energy } \\
\text { Resources }\end{array}$ & $\begin{array}{l}\text { Individual Re- } \\
\text { sources }\end{array}$ & $\begin{array}{l}\text { Aggregated Re- } \\
\text { sources }\end{array}$ & $\begin{array}{l}\text { Individual Re- } \\
\text { sources }\end{array}$ \\
\hline & $\begin{array}{l}\text { Key Energy-Re- } \\
\text { lated Customer } \\
\text { Value }\end{array}$ & $\begin{array}{l}\text { Efficiency \& Cost } \\
\text { Savings, Autarky } \\
\text { \& Access }\end{array}$ & Additional Income & $\begin{array}{l}\text { Efficiency \& Cost } \\
\text { Savings, Autarky } \\
\& \text { Access, Com- } \\
\text { fort }\end{array}$ \\
\hline & Type of Offering & Pure Digital & Pure Digital & $\begin{array}{l}\text { Smart Product- } \\
\text { Service-System }\end{array}$ \\
\hline & $\begin{array}{l}\text { Supporting Ser- } \\
\text { vices }\end{array}$ & Advice & $\begin{array}{l}\text { No Additional } \\
\text { Services }\end{array}$ & $\begin{array}{l}\text { No Additional } \\
\text { Services }\end{array}$ \\
\hline & Customer & Prosumer & Consumer & Prosumer \\
\hline \multirow{3}{*}{$\begin{array}{l}\text { Smart } \\
\text { Energy } \\
\text { Product }\end{array}$} & Capabilities & Control & Control & $\begin{array}{l}\text { Autonomous Sys- } \\
\text { tem }\end{array}$ \\
\hline & $\begin{array}{l}\text { Smart Product } \\
\text { Included }\end{array}$ & Storage-Related & $\begin{array}{l}\text { No Product In- } \\
\text { cluded }\end{array}$ & $\begin{array}{l}\text { Integration-Re- } \\
\text { lated }\end{array}$ \\
\hline & Ownership & Focal Company & Customer & Customer \\
\hline \multirow[t]{3}{*}{ Monetization } & $\begin{array}{l}\text { Customer Payment } \\
\text { Schedule }\end{array}$ & Subscription & None & $\begin{array}{l}\text { One-Time Pay- } \\
\text { ment }\end{array}$ \\
\hline & $\begin{array}{l}\text { Customer Cur- } \\
\text { rency }\end{array}$ & Money & Energy Resources & Money \\
\hline & Indirect Revenues & None & $\begin{array}{l}\text { Funding, Internal } \\
\text { Cost Savings \& } \\
\text { Optimizations }\end{array}$ & None \\
\hline
\end{tabular}

GridBox Energy Manager The energy manager by GridBox optimizes and maximizes all energy flow in the home. The fully automated offering helps its customers shift from consuming energy to using self-produced electricity, for instance, by controlling energy storage. This energy management is classified as efficient energy use and self-production and storage. The offering is for prosumers. Moreover, the energy manager supports integration with many systems, including PV systems, EV charging stations and heat pumps, from many vendors. Furthermore, the offering is a classic smart energy product-service system consisting of a physical smart hub (an integration-related smart energy product) and access to a web portal to display the energy flows. The smart energy offering is sold as a one-time payment with money as currency and no indirect revenue. 


\section{Discussion}

\subsection{Contribution to Business Research and Practice}

In highlighting the unique characteristics of smart energy services, the paper provides a more nuanced picture on the nature of smart energy services and their potential in terms of new consumer and business values. Since research has not yet provided theories and explanations on the design of smart energy services for new business and customer values, this study is exploratory and provides an analysis and classification of the new developments in the consumer-oriented smart energy service market which can serve as a fundament for quantitative and qualitative studies in the future.

By employing a smart service science lens (Beverungen et al. 2019; Vargo and Lusch 2004) and the smart product concept from Porter and Heppelmann (2014) this study provides a new perspective on smart energy services. Furthermore, the morphological analysis strengthens the conceptual foundation by exploring important elements that describe smart energy services. Particularly, the use of the S-D logic (Vargo and Lusch 2004, 2008) facilitates a better understanding of the strong interconnection between smart energy products and services and their underlying co-creation logic. Further, the S-D logic highlights the increasing customer participation in the value creation, for example, in the form of energy resources and data. In particular, the notion of smart energy products (Porter and Heppelmann 2014) facilitates a better explanation of how digitalization alters the provision of services.

Finally, the morphological box can be used to describe and analyze smart energy offerings as shown in Sect. 6. As there is a tendency towards individual and tailored solutions, ranging from supportive services to comprehensive full-service solutions, the proposed classification can support the configuration of complex service design options.

The classification can stimulate new methods of offering smart energy technology to customers. This is of particular importance in the private household sector, since energy customers often view energy as a commodity with which people have limited involvement (Kahma and Matschoss 2017). Depending on the design, a smart product can be presented as a completely different smart energy service offering. For instance, the company Nest offers its smart learning thermostat as a simple, onetime purchase, but the Nest Thermostat is also part of a utility partner program in which the thermostat is provided for free or at a discount. The thermostat is thus the central component for a residential demand response program.

Another contribution of the morphological analysis is that the services in the literature usually only provide insight into previously existing configurations of smart energy services. The findings of this work can expose potential new service configurations, so that the resulting morphological box can also be regarded as a service innovation tool (Peters et al. 2015).

\subsection{Implications for Research and Practice}

Several topics were identified that would be beneficial to explore in practice and in future research. Although there are characteristics that are not covered by the 
classified examples (e.g., digital service with human-based supporting service in the dimension type of offering or attention as a currency), the characteristics are regarded as relevant to the morphological box, as there may be examples in the future which could be classified using this characteristic. Hence, the morphological box is futureoriented and research could explore these characteristics.

Since most of the analyzed market offerings concentrate on the traditional sale paradigm, practitioners could concentrate on more advertising- and data-related monetization options. In particular, the decoupling of purchasing a physical product and offering additional digital services in terms of micropayments like "in-app purchases" for smartphone apps could generate additional revenue.

Furthermore, service providers could experiment with more performance- and usage-based payment models combined with service-oriented offerings. For example, a smart energy product could be supplied to the customer without any upfront costs and could be paid for based on its usage or performance; these factors could easily be monitored using smart technologies. Similar structures have already been implemented in other industries, such as the HP Instant Ink $k^{3}$ service, which is an automatic ink refilling service. The service monitors a printer's toner level and page consumption. More toner is automatically reordered every time the filling level reaches a critical level. The service is paid via a monthly scale price based on the number of printed pages.

Companies could also focus on pure digital (micro) services, like the asset management service by Greensynergy, which could be offered on a usage-based schedule and at a low price (e.g., a few cents or euros); these services would consequently be more attractive to private households.

Moreover, people could pay a flat rate for smart energy equipment. For instance, they could pay a subscription fee to use an unlimited number of smart home devices. The usage of the smart home devices would be monitored to ensure proper use, and people could be rewarded for their energy saving goals. Rewards for energy savings would be even more interesting if the provider were the energy supplier and were to offer the consumer energy at a flat rate (which itself could be calculated based on historic smart meter energy-usage patterns). Such service innovations would also decrease the high upfront costs that often accompany smart energy products.

Another service configuration would be to combine smart home and EV battery monitoring and controlling services. The use of the EV battery and its location could be monitored, so that charging can be scheduled according to the location and movement patterns. Moreover, a timer for switching on smart home devices like washing machine could be set depending on the time the EV battery can be used. The smart home system could detect if the user did not switch off the lights while leaving the smart home, so it could inform the home owner.

The above-mentioned service ideas were stimulated by our analysis in Sect. 6.1. The ideas could be further extended to a complete offering by using the morphological analysis.

Even though there are integrated energy management systems on the market combining different smart energy products, such as GridBox, these systems have

\footnotetext{
3 https://instantink.hpconnected.com (accessed 05 August 2019).
} 
low feasibility in terms of smart capabilities such as the use of artificial intelligence for autonomous actions. In general customers face closed ecosystems and limited features (e.g., only monitoring and controlling instead of sophisticated optimization and autonomous actions with several interconnected smart energy products). As such, research and practice should concentrate to enhance the smart capabilities and the integration of offerings.

With respect to data-related dimensions, the identified services were assessed based on their different levels of smart (i.e., data-driven) capabilities (e.g., monitoring, controlling, optimization or autonomy) (Porter and Heppelmann 2014). To create additional value, these smart capabilities could also be extended by considering the specific forms of data and analytics required for the services, since this consideration creates significant variations in the functionality and capability of the services. However, to gain deeper insight, this extension would require other research methods, for example, expert interviews, field trials or case studies.

During the market analysis, it further appeared to be important that companies advertise the smart capabilities with regard to their concrete values for the customers. For instance, if an energy manager is able to enhance the level of autarky, it should be communicated with concrete numbers to the customer.

In the future, value-added services, such as security and health services based on smart energy data, could become attractive. Such services would extend beyond the present form of the morphological box. For instance, due to the nature of energy data, one can monitor and analyze living patterns of inhabitants. Thus, assisted living monitoring service could be provided which detects the patterns of inhabitant's behavior and in case of anomalies, a customer service for assisted living can be informed to look for the inhabitant. Energy data can be also used to enable home security monitoring service by informing the home owner in case of anomalies in the own home. There might be broader application areas for smart energy services with more general platform approaches, such as the consumer-oriented Internet of Things platform geeny ${ }^{4}$.

Another research option is to adopt known (smart) service pattern from other industries to the energy sector, for instance, reorder subscription services similar to Amazon's Dash Buttons. They could be based on energy usage of specific devices (e.g., dishwasher), hence the need for refillment can be detected and items (e.g., dish washer tabs) can be reordered automatically ${ }^{5}$. Another service pattern which could be adapted from Amazon are cross-selling recommendations. By detecting new electronic purchases and monitoring of soon to be broken electronics, crossselling recommendations in a smart meter app could be made and would instantiate the currency attention in the morphological analysis.

\footnotetext{
4 https://next.telefonica.de/en/solutions/consumer-iot-platform (accessed 05 August 2019).

5 This service is already implemented by the smart meter company Fresh Energy; https://www.pvmagazine.de/unternehmensmeldungen/weltweit-erster-smart-meter-basierter-mehrwert-gestartet-refreshvon-fresh-energy-bietet-mehrwertdienste-fuer-stromkunden/ (accessed 05 August 2019).
} 


\subsection{Limitations}

This paper is subject to some limitations. Since a service classification can never be of truth value, there might be alternative viewpoints and classifications (see, for example, Salah et al. 2017). Moreover, the smart energy services field is still emergent, which mandates regular updates to the morphological box. Another limitation is the number of services that were surveyed and the assessment of these services, which relied on publicly available information on websites. Moreover, it has been difficult to identify if authors in the literature are referring to "smart" energy services, since the service descriptions are often not sufficiently informative.

The real-life examples were only categorized by two researchers. Thus, the classification might be biased by subjective interpretation. We tried to reduce the bias by regularly discussing the classified empirical objects. Moreover, the information on the websites did not always reveal if the companies exploit the data provided from the smart energy products for, for example, internal process optimizations or sale to third parties. Due to the sample size, the analysis of the occurrences cannot be regarded as representative; instead it provides initial in-depth insight into the characteristics of existing smart energy services.

Another limitation is that the analysis of the empirical objects indicated certain dependencies between the characteristics, e.g. between the dimension supporting services and smart energy product included (Ritchey 2011; Zwicky 1967). However, the identification of all dependencies would have extended beyond the scope of this paper.

We only considered money for the payment schedule (e.g., usage- and performance-based, one-time payment, subscription). However, for the future we could think that data as a currency could become more important so that customers could decide what kind of data and how often (i.e. payment mode) they would be willing to offer their data.

Moreover, the morphological box only considers energy-related values that are relevant to smart energy technologies created for residential customers. However, considering non-energy-related benefits and values would have threatened the classification's usefulness and increased its complexity. Research could be conducted to extend the classification and to identify and describe possible value-added services based on energy data and eventually other data sources from different domains (e.g., health, mobility, security or retail).

Finally, the energy sector is a highly regulated sector, and progress towards a smart grid varies from country to country. For instance, in Germany the smart meter rollout has yet to start, so demand response and smart meter-based tariffs are not available. When designing concrete services, one must consider national regulations.

\section{Conclusion}

Due to rise of the Internet of Things in the energy industry, smart energy services are becoming more important as they are embedded in and enabled by smart products. Understanding the value-creation logic of smart energy services and their individual 
elements is essential for companies in the energy sector when designing innovative services. Since research has not yet provided theories and explanations on the design of smart energy services for new business and customer values, this study is an exploratory study and provides an analysis and classification of the new developments in the consumer-oriented smart energy service market which can serve as a fundament for future quantitative and qualitative studies. In highlighting the unique characteristics of smart energy services, the paper provides a more nuanced picture on the nature of smart energy services and their potential in terms of new consumer and business values.

This study applied an iterative, conceptually and empirically driven development approach was adapted from design science research (Hevner et al. 2004; Hevner 2007 ) and Zwicky's morphological analysis (1948, 1967). The literature review facilitated the development of a rigorous classification system, and the analysis of empirical cases enhanced the relevance of the morphological box (Hevner 2007). The classification of a larger number of empirical services finally helped to verify whether and how self-explanatory and instinctively the real-life services could be assigned to various dimensions and characteristics (Oberländer et al. 2018). Furthermore, additional details based on the occurrences of single smart energy service characteristics were revealed, which led to concrete ideas and recommendations for the design of new smart energy services.

In conclusion, the morphological box for smart energy service design supplements the existing knowledge base by building on extant research on smart services and transferring this knowledge to the energy domain. The morphological box can foster the analysis and design of smart energy services. The layered architecture (with the layers smart energy service, smart energy product, and monetization) enables a comprehensive perspective on smart energy services. The monetization perspective in particular supports companies in exploiting the business potential emerging from smart energy services. By strengthening the conceptual foundation on smart energy services, this paper might encourage future work on this important topic. 


\section{Appendix}

Table 2 List of Empirical Objects Classified (services whose cells have a gray background were used to develop the morphological box; websites accessed 05 August 2019)

\begin{tabular}{|c|c|c|c|}
\hline ID & Company & Smart Service Offering & Website \\
\hline 1 & AC Heating & AC Heating & https://www.ac-heating.ie/heat-pumps/ \\
\hline 2 & AirPatrol & SmartSocket & https://www.airpatrol.eu/smartsocket/ \\
\hline 3 & Amphiro & Amphiro a1 basic & https://www.amphiro.com/en/ \\
\hline 4 & BGE & $\begin{array}{l}\text { Thermostat Optimization Pro- } \\
\text { gram }\end{array}$ & $\begin{array}{l}\text { https://bgesmartenergy.com/residential/ } \\
\text { optimization }\end{array}$ \\
\hline 5 & Buzzn & $\begin{array}{l}\text { Buzzn Energiegruppe (own smart } \\
\text { meter available) }\end{array}$ & https://www.buzzn.net/ \\
\hline 6 & Caterva & $\begin{array}{l}\text { Caterva "Sun" (participation in } \\
\text { flexibility program) }\end{array}$ & $\begin{array}{l}\text { https://www.caterva.de/?produkte\# } \\
\text { caterva-sonnen }\end{array}$ \\
\hline 7 & ChargePoint & $\begin{array}{l}\text { ChargePoint Home (with govern- } \\
\text { mental funding) }\end{array}$ & $\begin{array}{l}\text { https://www.chargepoint.com/drivers/ } \\
\text { home/ }\end{array}$ \\
\hline 8 & ConEdison & Smart Upgrade EV Charger & https://bit.ly/2ikkXZe \\
\hline 9 & ConEdison & Smart Meter & https://bit.ly/2umSS8O \\
\hline 10 & Daje & P2P local Energy Sharing & https://www.dajie.eu/ \\
\hline 11 & Discovergy & Smart Meter for PV/CHP & https://bit.ly/2YdN947 \\
\hline 12 & $\mathrm{DZ}-4$ & DZ-4 Easy smart & https://www.dz-4.de/produkte \\
\hline 13 & E.ON & SolarCloud & $\begin{array}{l}\text { https://www.eon-solar.de/eon- } \\
\text { solarcloud }\end{array}$ \\
\hline 14 & Ecobee & Ecobee (smart thermostat) & https://www.ecobee.com/ecobee4/ \\
\hline 15 & Ecocoach & Ecocoach battery & $\begin{array}{l}\text { https://ecocoach.com/loesungen/ } \\
\text { batteriespeicher }\end{array}$ \\
\hline 16 & Ecoisme & Ecoisme energy monitor & https://ecoisme.com/ \\
\hline 17 & Electric Kiwi & Power supply & https://www.electrickiwi.co.nz/ \\
\hline 18 & $\begin{array}{l}\text { Emporia } \\
\text { Energy }\end{array}$ & Emporia Vue & $\begin{array}{l}\text { https://emporiaenergy.com/smart- } \\
\text { energy-home-system/ }\end{array}$ \\
\hline 19 & EnBW & EnBW solar+ & https://www.enbw.com/solar \\
\hline 20 & Enphase & Enphase Home Energy Solution & https://bit.ly/2YdNEev \\
\hline 21 & Ev.energy & EV.energy App & $\begin{array}{l}\text { https://ev.energy/solutions/smart- } \\
\text { charging-download-app/ }\end{array}$ \\
\hline 22 & EVBOX & Elvi + Hey by EVBox app & https://evbox.com/ \\
\hline 23 & EWE AG & MyEnergyCloud & https://www.ewe.de/myenergycloud \\
\hline 24 & Fujitsu & Heat Pump E3 WiFi Edition & $\begin{array}{l}\text { https://www.fujitsugeneral.co.nz/hi- } \\
\text { wall-range/e3-wifi-edition }\end{array}$ \\
\hline 25 & Greenlots & Greenlots App & https://greenlots.com/ev-drivers/ \\
\hline 26 & Greensynergy & PV Monitoring & $\begin{array}{l}\text { https://www.greensynergy.de/ } \\
\text { anlagenbetreiber/ }\end{array}$ \\
\hline 27 & GridX & GridBox & https://gridx.de/produkt/gridbox/ \\
\hline 28 & Innogy & $\begin{array}{l}\text { Innogy Smart Home Paket En- } \\
\text { ergy }\end{array}$ & https://bit.ly/2oi0Zg9 \\
\hline 29 & Innogy & Premium Auswertungen & https://bit.ly/2LUATOP \\
\hline 30 & Jedlix & Jedlix App for Smart Charging & https://jedlix.com/en/ \\
\hline
\end{tabular}


Table 2 (Continued)

\begin{tabular}{|c|c|c|c|}
\hline ID & Company & Smart Service Offering & Website \\
\hline 31 & Meo-Energy & Meo Box & https://bit.ly/2LOaNOD \\
\hline 32 & Mixergy & Mixergy Tank & $\begin{array}{l}\text { https://www.mixergy.co.uk/mixergy- } \\
\text { tank/ }\end{array}$ \\
\hline 33 & Nest & Nest Learning Thermostat & https://bit.ly/2MqPaTK \\
\hline 34 & Nest & Nest Utility Partner Program & $\begin{array}{l}\text { https://nest.com/energy-solutions/\# } \\
\text { rush-hour }\end{array}$ \\
\hline 35 & NewMotion & $\begin{array}{l}\text { Dynamic Power Management } \\
\text { (upgrade) }\end{array}$ & https://bit.ly/2HXuGiD \\
\hline 36 & OhmConnect & $\begin{array}{l}\text { Residential Demand Response } \\
\text { Program }\end{array}$ & https://www.ohmconnect.com/ \\
\hline 37 & OvoEnergy & OVO Vehicle-To-Grid Charger & https://bit.ly/2OeDIsh \\
\hline 38 & OvoEnergy & $\begin{array}{l}\text { EV Everywhere bundle (home } \\
\text { energy plan) }\end{array}$ & $\begin{array}{l}\text { https://www.ovoenergy.com/ev- } \\
\text { everywhere/smart-charger }\end{array}$ \\
\hline 39 & SCE & $\begin{array}{l}\text { Smart Energy Program (own } \\
\text { thermostat available) }\end{array}$ & https://on.sce.com/2LnOBtY \\
\hline 40 & $\begin{array}{l}\text { SENEC } \\
\text { GmbH }\end{array}$ & SENEC Cloud & https://www.senec.com/cloud \\
\hline 41 & Sense & Sense Home Energy Monitor & https://sense.com/product.html \\
\hline 42 & SOLARWATT & $\begin{array}{l}\text { Solarwatt complete bundle } \\
\text { "store" }\end{array}$ & https://bit.ly/2ym0SXn \\
\hline 43 & Sonnen & $\begin{array}{l}\text { SonnenFlathome (sonnenCom- } \\
\text { munity Prosumer) }\end{array}$ & https://sonnen.de/sonnencommunity/ \\
\hline 44 & $\begin{array}{l}\text { Stadtwerke } \\
\text { Leipzig }\end{array}$ & Leipziger Sorglos-Servicepaket & https://bit.ly/2SRZ9Ct \\
\hline 45 & $\begin{array}{l}\text { Stadtwerke } \\
\text { München }\end{array}$ & M-Solar-Plus (with smart plugs) & https://bit.ly/2YuFLgb \\
\hline 46 & Sunverge & Sunverge One & $\begin{array}{l}\text { http://www.sunverge.com/customer- } \\
\text { solutions/ }\end{array}$ \\
\hline 47 & Tado & $\begin{array}{l}\text { Tado Smart Thermostat + op- } \\
\text { tional "Auto-Assist" }\end{array}$ & $\begin{array}{l}\text { https://www.tado.com/de/produkte/ } \\
\text { smartes-zusatz-thermostat }\end{array}$ \\
\hline 48 & $\begin{array}{l}\text { The Plugin } \\
\text { Company }\end{array}$ & Smart Charging Home & $\begin{array}{l}\text { http://www.theplugincompany.com/ } \\
\text { smarthomeen.html }\end{array}$ \\
\hline 49 & PG\&E & Tired Rate Plan & https://bit.ly/2JCDTxP \\
\hline 50 & Wattio & Smart Home Pack Energy & https://wattio.com/en/ \\
\hline 51 & Zome & $\begin{array}{l}\text { ZomeHome Smart Energy Pro- } \\
\text { gram }\end{array}$ & https://zomepower.com/zomehome \\
\hline
\end{tabular}

Acknowledgements This paper has been written in context of the research project "VISE: Virtuelles Institut Smart Energy" (https://www.smart-energy.nrw/). The project is funded by the "Europäischen Fonds für regionale Entwicklung (EFRE) 2014-2020”.

Funding The project is funded by the "Europäischen Fonds für regionale Entwicklung (EFRE) 2014-2020”. By stating the EFRE funding, we have disclosed all interest fully to SBUR.

Author Contribution Both authors contributed to the development of the research.

Funding Open Access funding enabled and organized by Projekt DEAL. 
Open Access This article is licensed under a Creative Commons Attribution 4.0 International License, which permits use, sharing, adaptation, distribution and reproduction in any medium or format, as long as you give appropriate credit to the original author(s) and the source, provide a link to the Creative Commons licence, and indicate if changes were made. The images or other third party material in this article are included in the article's Creative Commons licence, unless indicated otherwise in a credit line to the material. If material is not included in the article's Creative Commons licence and your intended use is not permitted by statutory regulation or exceeds the permitted use, you will need to obtain permission directly from the copyright holder. To view a copy of this licence, visit http://creativecommons.org/licenses/by/4.0/.

\section{References}

Alexander von Humboldt Institut, and co2online. 2018. Smart Energy in Deutschland: Wie Nutzerinnovationen die Energiewende voranbringen. https://www.hiig.de/wp-content/uploads/2018/02/SmartEnergy-Technologien_web.pdf. Accessed 20 June 2019.

Apajalahti, E.-L., R. Lovio, and E. Heiskanen. 2015. From demand side management (DSM) to energy efficiency services: a Finnish case study. Energy Policy 81:76-85.

Beverungen, D., O. Müller, M. Matzner, J. Mendling, and J. vom Brocke. 2019. Conceptualizing smart service systems. Electronic Markets 29(1):7-18.

Bhatti, H.J., and M. Danilovic. 2018. Business model innovation approach for commercializing smart grid systems. American Journal of Industrial and Business Management 8(9):2007-2051.

Bischoff, D., M. Kinitzki, T. Wilke, F. Zeqiraj, S. Zivkovic, C. Koppenhöfer, J. Fauser, et al. 2017. Smart meter based business models for the electricity sector-A systematical literature research. In Proceedings of the 3rd Digital Enterprise Computing Conference (DEC 2017), Böblingen, Germany, 79-90.

Bundesnetzagentur. 2019. Flexibilität im Stromversorgungssystem. https://www.bundesnetzagentur.de/ DE/Sachgebiete/ElektrizitaetundGas/Unternehmen_Institutionen/NetzentwicklungundSmartGrid/ Flexibilitaet/Flexibilitaet_node.html. Accessed 25 Mar 2019.

Byun, J., I. Hong, B. Kang, and S. Park. 2011. A smart energy distribution and management system for renewable energy distribution and context-aware services based on user patterns and load forecasting. Consumer Electronics, IEEE Transactions On 57(2):436-444.

Camarinha-Matos, L.M. 2016. Collaborative smart grids-A survey on trends. Renewable and Sustainable Energy Reviews 65:283-294.

Fettke, P., and P. Loos. 2003. Classification of reference models: a methodology and its application. Information Systems and E-Business Management 1(1):35-53.

Fleisch, E., M. Weinberger, and F. Wortmann. 2014. Geschäftsmodelle im Internet der Dinge. HMD Praxis Der Wirtschaftsinformatik 51:812-826.

Ford, R., M. Pritoni, A. Sanguinetti, and B. Karlin. 2017. Categories and functionality of smart home technology for energy management. Building and Environment 123:543-554.

Fox-Penner, P. 2009. Fix utilities before they need a rescue. Harvard Business Review 87(10):132-132.

Geelen, D., D. Keyson, S. Boess, and H. Brezet. 2012. Exploring the use of a game to stimulate energy saving in households. Journal of Design Research 10(1/2):102.

Geelen, D., A. Reinders, and D. Keyson. 2013. Empowering the end-user in smart grids: Recommendations for the design of products and services. Energy Policy 61:151-161.

Gimpel, H., D. Rau, and M. Röglinger. 2017. Understanding FinTech start-ups-A taxonomy of consumeroriented service offerings. Electronic Markets. https://doi.org/10.1007/s12525-017-0275-0

Giordano, V., and G. Fulli. 2012. A business case for Smart Grid technologies: A systemic perspective. Energy Policy 40(1):252-259.

Goebel, C., H.-A. Jacobsen, V. del Razo, C. Doblander, J. Rivera, J. Ilg, C. Flath, et al, 2014. Energy informatics-Current and future research directions. Business \& Information Systems Engineering 6(1):25-31.

Goedkoop, M.J., C.J.G. Van Halen, H.R.M. Te Riele, and P.J.M. Rommens. 1999. Product service systems, ecological and economic basics, vol. 36. http://teclim.ufba.br/jsf/indicadores/holan Product Service Systems main report.pdf. Accessed 30 Nov 2019.

Goldbach, K., A.M. Rotaru, S. Reichert, G. Stiff, and S. Gölz. 2018. Which digital energy services improve energy efficiency? A multi-criteria investigation with European experts. Energy Policy 115:239-248.

Hamwi, M., and I. Lizarralde. 2017. A review of business models towards service-oriented electricity systems. Procedia CIRP 64:109-114. 
Hamwi, M., I. Lizarralde, J. Legardeur, T. Izarbel, and B. France. 2016. Energy product service systems as core element of energy transition in the household sector: the Greenplay project. In Proceedings of the 22nd International Sustainable Development Research Society Conference, Lisbon, Portugal.

Heiskanen, E., and K. Matschoss. 2016. Consumers as innovators in the electricity sector? Consumer perceptions on smart grid services. International Journal of Consumer Studies 40(6):665-674.

Helms, T. 2016. Asset transformation and the challenges to servitize a utility business model. Energy Policy 91:98-112.

Hevner, A.R. 2007. A three cycle view of design science research. Scandinavian Journal of Information Systems 19(2):87-92.

Hevner, A., S.T. March, J. Park, and S. Ram. 2004. Design science in information systems research. MIS Quarterly 28(1):75.

Hui, G. 2014. How the internet of things changes business models. Harvard Business Review 92(7/8):1-5.

Hyytinen, K., and M. Toivonen. 2015. Future energy services: empowering local communities and citizens. In Foresight, Vol. 17, ed. D. Cox, L. Green, and K. Borodako, 349-364. Bingley: Emerald Group.

International Energy Agency. 2015. How 2 guide for: smart grids in distribution networks. https://www.iea. org/publications/freepublications/publication/TechnologyRoadmapHow2GuideforSmartGridsinDist ributionNetworks.pdf. Accessed 27 Nov 2018.

Kahma, N., and K. Matschoss. 2017. The rejection of innovations? Rethinking technology diffusion and the non-use of smart energy services in Finland. Energy Research and Social Science 34:27-36.

Karnouskos, S. 2011. Future smart grid prosumer services. In IEEE PES Innovative Smart Grid Technologies Conference Europe, 1-2.

Karnouskos, S. 2013. Smart houses in the smart grid and the search for value-added services in the cloud of things era. In Proceedings of the IEEE International Conference on Industrial Technology, 2016-2021.

Kley, F., C. Lerch, and D. Dallinger. 2011. New business models for electric cars-A holistic approach. Energy Policy 39(6):3392-3403.

Koirala, B.P., E. Koliou, J. Friege, R.A. Hakvoort, and P.M. Herder. 2016. Energetic communities for community energy: A review of key issues and trends shaping integrated community energy systems. Renewable and Sustainable Energy Reviews 56:722-744.

Kranz, J., L.M. Kolbe, C. Koo, and M.C. Boudreau. 2015. Smart energy: where do we stand and where should we go? Electronic Markets 25(1):7-16.

Lasseter, R.H. 2002. MicroGrids. In Proceedings of the IEEE Power Engineering Society Winter Meeting Conference, New York.

Liu, J., N. Zhang, C. Kang, D. Kirschen, and Q. Xia. 2017. Cloud energy storage for residential and small commercial consumers: A business case study. Applied Energy 188:226-236.

Löbbe, S., and A. Hackbarth. 2017. The transformation of the German electricity sector and the emergence of new business models in distributed energy systems. Innovation and Disruption at the Grid's Edge. https://doi.org/10.1016/B978-0-12-811758-3.00015-2

Lund, H., A.N. Andersen, P.A. Østergaard, B.V. Mathiesen, and D. Connolly. 2012. From electricity smart grids to smart energy systems-A market operation based approach and understanding. Energy 42(1):96-102.

Lusch, R.F., and S. Nambisan. 2015. Service innovation: a service-dominant logic perspective. MIS Quarterly 39(1):155-175.

Maglio, P.P., and C.-H. Lim. 2016. Innovation and big data in smart service systems. Journal of Innovation Management 4(1):11-21.

Martin-Martínez, F., Á. Sánchez-Miralles, and M. Rivier. 2016. A literature review of Microgrids: a functional layer based classification. Renewable and Sustainable Energy Reviews 62:1133-1153.

Mejtoft, T. 2011. Internet of Things and co-creation of value. In 2011 International Conference on Internet of Things and 4th International Conference on Cyber, Physical and Social Computing, IEEE, $672-677$.

Mittag, T., M. Rabe, T. Gradert, A. Kühn, and R. Dumitrescu. 2018. Building blocks for planning and implementation of smart services based on existing products. Procedia CIRP 73:102-107.

Niesten, E., and F. Alkemade. 2016. How is value created and captured in smart grids? A review of the literature and an analysis of pilot projects. Renewable and Sustainable Energy Reviews 53:629-638.

NIST. 2014. NIST framework and roadmap for smart grid Interoperability standards, release 3.0. https:// nvlpubs.nist.gov/nistpubs/SpecialPublications/NIST.SP.1108r3.pdf. Accessed 15 Apr 2018.

Oberländer, A.M., M. Röglinger, M. Rosemann, and A. Kees. 2018. Conceptualizing business-to-thing interactions-A sociomaterial perspective on the Internet of Things. European Journal of Information Systems 27(4):486-502. 
Osterwalder, A., and Y. Pigneur. 2010. Business model generation: a handbook for visionaries, game changers, and challengers, a handbook for visionaries, game changers, and challengers. New Jersey: Wiley.

Paukstadt, U. 2019. A Survey of Smart Energy Services for Private Households. Proceedings of the 14th International Conference on Wirtschaftsinformatik (WI 2019), Siegen, Germany.

Paukstadt, U., and Becker, J. 2019. Uncovering the business value of the internet of things in the energy domain - a review of smart energy business models. Electronic Markets, Electronic Markets. https:// doi.org/10.1007/s12525-019-00381-8.

Paukstadt, U., Gollhardt, T., Blarr, M., Chasin, F., and Becker, J. 2019a. A Consumer-oriented Smart Energy Business Model Taxonomy. Proceedings of the 27th European Conference on Information Systems (ECIS 2019), Stockholm and Uppsala, Sweden.

Paukstadt, U., Strobel, G., and Eicker, S. 2019b. Understanding Services in the Era of the Internet of Things: A Smart Service Taxonomy. Proceedings of the 27th European Conference on Information Systems, Stockholm and Uppsala, Sweden.

Peters, C., I. Blohm, and J.M. Leimeister. 2015. Anatomy of successful business models for complex services: insights from the telemedicine field. Journal of Management Information Systems 32(3):75-104.

Pitì, A., G. Verticale, C. Rottondi, A. Capone, and L. Lo Schiavo. 2017. The role of smart meters in enabling real-time energy services for households: The Italian case. Energies 10(2):1-25.

Porter, M.E., and J.E. Heppelmann. 2014. How smart, connected products are transforming competition. Harvard Business Review 92(11):64-88.

Pousttchi, K., and Y. Hufenbach. 2011. Value creation in the mobile market: A reference model for the role(s) of the future mobile network operator. Business and Information Systems Engineering 3(5):299-311.

Richter, M. 2012. Utilities' business models for renewable energy: A review. Renewable and Sustainable Energy Reviews 16(5):2483-2493.

Richter, L.-L., and M.G. Pollitt. 2018. Which smart electricity service contracts will consumers accept? The demand for compensation in a platform market. Energy Economics 72:436-450.

Ritchey, T. 2011. General Morphological Analysis (GMA). In Wicked problems-Social messes, 7-18. Berlin, Heidelberg, New York: Springer.

Rodríguez-Molina, J., J.-F. Martínez, and P. Castillejo. 2016. A study on applicability of distributed energy generation, storage and consumption within small scale facilities. Energies 9(9):745.

Rodríguez-Molina, J., M. Martínez-Núñez, J.F. Martínez, and W. Pérez-Aguiar. 2014. Business models in the smart grid: challenges, opportunities and proposals for prosumer profitability. Energies 7(9):6142-6171.

Salah, F., C.M. Flath, A. Schuller, C. Will, and C. Weinhardt. 2017. Morphological analysis of energy services: Paving the way to quality differentiation in the power sector. Energy Policy 106:614-624.

Shomali, A., and J. Pinkse. 2016. The consequences of smart grids for the business model of electricity firms. Journal of Cleaner Production 112:3830-3841.

Strobel, G., Paukstadt, U., Becker, J.J., and Eicker, S. 2019. Von smarten Produkten zu smarten Dienstleistungen und deren Auswirkung auf die Wertschöpfung. HMD - Praxis Der Wirtschaftsinformatik, $56(327)$.

Strüker, J., H. Weppner, and G. Bieser. 2011. Intermediaries for the Internet of energy-Exchanging smart meter data as a business model. In Proceedings of the 19th European Conference on Information Systems (ECIS 2011), Helsinki, Finland.

Turber, S., J. Vom Brocke, O. Gassmann, and E. Fleisch. 2014. Designing business models in the era of Internet of Things: Towards a reference framework. In DESRIST 2014, 17-31. Cham: Springer.

Valencia, A., R. Mugge, J.P.L. Schoormans, and H.N.J. Schifferstein. 2015. The design of smart productservice systems (PSss): An exploration of design characteristics. International Journal of Design 9(1):13-28.

Van Dam, S.S., C.A. Bakker, and J.D.M. Van Hal. 2010. Home energy monitors: impact over the mediumterm. Building Research and Information 38(5):458-469.

Vargo, S.L., and R.F. Lusch. 2004. Evolving to a new dominant logic for marketing. Journal of Marketing 68(1):1-17.

Vargo, S.L., and R.F. Lusch. 2008. Service-dominant logic: continuing the evolution. Journal of the Academy of Marketing Science 36(1):1-10.

Vytelingum, P., S.D. Ramchurn, T.D. Voice, A. Rogers, and N.R. Jennings. 2010. Trading agents for the smart electricity grid. In Proceedings of the 9th International Conference on Autonomous Agents and Multiagent Systems (AAMAS), Canada, 897-904. 
Weiller, C., and A. Neely. 2014. Using electric vehicles for energy services: Industry perspectives. Energy 77:194-200.

Wu, C., B.B. Wang, and Y. Li. 2012. Research on electricity value-added services and development strategy for smart grid. In Proceedings of the China International Conference on Electricity Distribution (CICED 2012), Shanghai, China.

Wünderlich, N.V., K. Heinonen, A.L. Ostrom, L. Patricio, R. Sousa, C. Voss, and J.G. Lemmink. 2015. 'Futurizing' smart service: implications for service researchers and managers. Journal of Services Marketing 29(6/7):442-447.

Wunderlich, P., J. Kranz, D. Totzek, D. Veit, and A. Picot. 2012. The impact of endogenous motivations on adoption of IT-enabled services: the case of transformative services in the energy sector. Journal of Service Research 16(3):356-371.

Yoo, Y., R.J. Boland, K. Lyytinen, and A. Majchrzak. 2012. Organizing for innovation in the digitized world. Organization Science 23(5):1398-1408.

Yoo, Y., O. Henfridsson, and K. Lyytinen. 2010. Research commentary-The new organizing logic of digital innovation: an agenda for information systems research. nformation Systems Research 21(4):724-735.

Zhang, S. 2016. Innovative business models and financing mechanisms for distributed solar PV (DSPV) deployment in China. Energy Policy 95:458-467.

Zwicky, F. 1948. The morphological method of analysis and construction. California Inst. of Technol.

Zwicky, F. 1967. The morphological approach to discovery, invention, research and construction. In New methods of thought and procedure, 273-297. Berlin, Heidelberg, New York: Springer. 